\title{
A weakly-constrained data assimilation approach to address rainfall-runoff model structural inadequacy in streamflow prediction
}

\author{
Haksu Lee ${ }^{\mathrm{a}, *}$, Dong-Jun Seo ${ }^{\mathrm{b}}$, Seong Jin Noh ${ }^{\mathrm{b}}$ \\ ${ }^{a}$ LEN Technologies, Oak Hill, Virginia, U.S.A. \\ ${ }^{\mathrm{b}}$ Department of Civil Engineering, The University of Texas at Arlington, Arlington, Texas, U.S.A. \\ * Corresponding author: haksulee@ @hanmail.net \\ Tel.: +1 240-413-1133 \\ Postal address: 8750 Georgia Ave. 603B, Silver Spring, MD 20910, U.S.A.
}

Submitted to Journal of Hydrology

July 13, 2016

(C) 2016. This manuscript version is made available under the Elsevier user license http://www.elsevier.com/open-access/userlicense/1.0/ 


\begin{abstract}
This paper presents a simple yet effective weakly-constrained (WC) data assimilation (DA) approach for hydrologic models which accounts for model structural inadequacies associated with rainfall-runoff transformation processes. Compared to the strongly-constrained (SC) DA, WC DA adjusts the control variables less while producing similarly or more accurate analysis. Hence the adjusted model states are dynamically more consistent with those of the base model. The inadequacy of a rainfall-runoff model was modeled as an additive error to runoff components prior to routing and penalized in the objective function. Two example modeling applications, distributed and lumped, were carried out to investigate the effects of the WC DA approach on DA results. For distributed modeling, the distributed Sacramento Soil Moisture Accounting (SAC-SMA) model was applied to the TIFM7 Basin in Missouri, USA. For lumped modeling, the lumped SAC-SMA model was applied to nineteen basins in Texas. In both cases, the variational DA (VAR) technique was used to assimilate discharge data at the basin outlet. For distributed SAC-SMA, spatially homogeneous error modeling yielded updated states that are spatially much more similar to the a priori states, as quantified by Earth Mover's Distance (EMD), than spatially heterogeneous error modeling by up to 10 times. DA experiments using both lumped and distributed SAC-SMA modeling indicated that assimilating outlet flow using the WC approach generally produce smaller
\end{abstract}


mean absolute difference as well as higher correlation between the a priori and the updated states than the SC approach, while producing similar or smaller root mean square error of streamflow analysis and prediction. Large differences were found in both lumped and distributed modeling cases between the updated and the a priori lower zone tension and primary free water contents for both WC and SC approaches, indicating possible model structural deficiency in describing low flows or evapotranspiration processes for the catchments studied. Also presented are the findings from this study and key issues relevant to WC DA approaches using hydrologic models.

Key words: Model error, Weakly-constrained approach, Data assimilation, Streamflow

\section{Introduction}

No environmental models are structurally perfect which has been described in literatures as, e.g., model inadequacy, model deficiency, structural noise, or model error (Oreskes et al., 1994;

Beven, 2005, 2008; Beven et al., 2011; Bredehoeft, 2005; Doherty and Welter, 2010; Gupta et al., 2012; Montanari and Di Baldassarre, 2013). A number of techniques have been developed in order to account for model structural inadequacy, explicitly or implicitly, as a part of modeling total error, for example, Bayesian model averaging (BMA; Hoeting et al., 1999), BMA with data assimilation (Parrish et al., 2012), Bayesian total error analysis (Kuczera et al., 2006), multi-model ensemble 
forecasting (Adams and Ostrowski, 2010; Palmer et al., 2004), post-processing (van Andel et al., 2013 and references therein), to mention several. Similarly, data assimilation (DA) researchers in the area of atmosphere, meteorology, or ocean modeling used so-called a weakly-constrained (WC) approach in which the model is applied as a weak-constraint to DA problems (Eknes and Evensen, 1995; Zupanski, 1997; Uboldi and Kamachi, 2000; Di Lorenzo et al., 2007) by explicitly introducing model error terms in model equations and/or an objective function, as opposed to a strongly-constrained (SC) DA approach. Due to different levels of complexities and nonlinearities of hydrologic models relative to atmospheric, weather, or ocean models, the degree of improvement seen in the latter may not be linearly transferrable to the former. In hydrology, Seo et al. (2009) used a WC DA approach in assimilating outlet flow observations via the variational DA (VAR) technique developed for the lumped SAC-SMA; however, the performance difference between the WC and SC DA approaches was not investigated.

The structure and property of a model error needs to be specified in order to model it within a WC DA framework, e.g., time varying or spatially heterogeneous. Unknown characteristics of model errors are largely because of flexibilities in the process of developing a model by stitching together different assumptions, simplifications, approximations, or conceptualizations. To model unknown model errors, a parsimonious approach may be preferred because it is less subject to the overfitting problem but still mitigates the negative impact of model error to assimilation results as 
much as it can. Because rainfall-runoff transformation (amplitude) is an inherently different process from the routing (timing), separate error modeling for either model may be considered. Given that the error in the routing process may not be easily understood due to its timing-related behaviour, this study focuses on the error in the former, as the first attempt of research in this direction in hydrology. Details on hydrologic WC DA problem formulation and case study results are given in Sections 2 and 3, respectively.

Proper error modeling should produce expected assimilation results. Errors may leave compensatory effects to state variables or parameters. As calibrated parameters may compensate for all other error sources unaccounted during the calibration, updated states from a SC DA approach may be over-adjusted in order to compensate for model errors. If model errors are properly accounted, states are likely less adjusted with at least similar performance in analysis and prediction to SC DA results. This also reduces a risk to break the dynamically consistent spatiotemporal structure of a priori states, in a multi-dimensional state space, driven by the model dynamics. As accurate a priori parameters contain valuable information at ungauged locations (Zhang et al., 2012), the a priori states that result from the model dynamics (Schulz et al., 2006) can also provide spatiotemporally coherent information across the model domain. In operational hydrology, model soil moisture states are rarely observed at the scale of modeling. The principle of parsimony (Hawkins, 2004) states that, in the absence of observational evidence, the a priori states should be 
adjusted as little as possible.

Quantification of the effects of a WC approach on assimilation results should focus on control variables in addition to output variables, i.e., streamflow; many studies mainly investigate changes in the accuracy and spread of simulated flows caused by uncertainty in other variables or error sources (Michaud and Sorooshian, 1994; Eckhardt et al., 2003; Carpenter and Georgakakos, 2004; Feyen et al., 2007). Commonly available streamflow observations as well as the notion of a model error as "model-to-measurement misfit that cannot be ascribed to measurement noise" (Doherty and Welter, 2010) may increase the reliance of uncertainty analysis focused primarily on streamflow. However, verifying flow alone may be insufficient because of its integrated nature and muted information about errors in individual model constituents; for example, overly-adjusted states or parameters may reduce uncertainties in simulated flow which does not mean reduced errors in the former. In the previous paragraph, we argued that, compared to a SC DA approach, a WC DA approach may less adjust state variables, hence dynamically more consistent with a priori states, but still achieve similar model performance. Dynamical consistency between a priori and updated states in space and time may be measured via correlation or similarity-based metrics (Roche et al., 1998; Rubner et al., 2000; Wealands et al., 2005; Cha, 2007).

This study aims to present how to formulate and solve a WC DA problem for both distributed and lumped hydrologic models, investigate updated states as well as flow generated from a WC DA 
approach comparatively with corresponding results from a SC DA approach, and discuss issues associated with WC DA approaches from the perspective of hydrologic modeling. The model and DA technique used are Sacramento Soil Moisture Accounting (SAC-SMA) and VAR, respectively. Distributed SAC-SMA was applied to a basin in Missouri and lumped SAC-SMA to nineteen basins in Texas.

This paper is organized as follows. Section 2 describes hydrologic models used, formulation of general hydrologic DA problem as well as the WC DA problems specific to distributed or lumped modeling, study area, and evaluation metrics. Section 3 presents case studies of applying a WC DA approach to both distributed and lumped modeling and summarizes its results in comparison to SC DA results. Section 4 discusses issues associated with WC DA approaches from the viewpoint of hydrologic modeling. Finally, Section 5 presents a summary and a concluding remark.

\section{Methodology}

Subsection 2.1 describes the lumped as well as distributed SAC-SMA models in Subsections

2.1.1 and 2.1.2, respectively. Subsection 2.2 describes the hydrologic data assimilation problem in generality followed by formulation of the WC DA problems for the distributed and lumped SACSMA models in Subsections 2.2.1 and 2.2.2, respectively. Subsection 2.3 describes the study area and Subsection 2.4 summarizes the evaluation metrics used in this study. 


\subsection{Hydrological model}

\subsubsection{Lumped SAC-SMA}

The lumped Sacramento Soil Moisture Accounting (SAC-SMA; Burnash et al. 1973) model conceptualizes rainfall-runoff transformation processes focused on parameterizing soil moisture characteristics. The SAC-SMA is available within the Community Hydrologic Prediction System (CHPS) of the US National Weather Service and has been used in most RFCs to issue flood forecasts on a daily basis throughout the US. The SAC-SMA inputs include Mean Areal Precipitation (MAP) and Mean Areal Potential Evapotranspiration (MAPE), and the output is the Total Channel Inflow (TCI) from two subsurface soil storages-Upper Zone (UZ) and Lower Zone (LZ) — plus the overland flow zone. The LZ is normally much thicker than the UZ, and contains the majority of soil moisture to meet the evapotranspiration demand. In addition, the LZ is the primary source of baseflow fed to the channel. In the UZ, soil moisture is divided into tension and free water content, or UZTWC and UZFWC, respectively. Similarly, the LZ soil moisture states are composed of tension water (LZTWC), and supplemental and primary free water (LZFSC and LZFPC, respectively). Together with five soil moisture states, tension water contents (ADIMC) in the additional impervious area (ADIMP) generate fast and slow runoffs. Fast response components of 
TCI include surface, impervious and direct runoff, and slow response components include interflow and supplemental and primary ground water runoff (Koren et al., 2004). Surface runoff occurs in the case of fully saturated upper zone free water storage and precipitation rate exceeding the rate of interflow and percolation. Impervious runoff is generated from permanent impervious areas (PCTIM) and direct runoff is from the ADIMP. The TCI from the SAC-SMA is routed through a unit hydrograph (UH; Nash, 1957) to obtain streamflow at the outlet of a basin. The SAC-SMA model used in this study operates on an hourly time step. The Adjoint-Based OPTimizer (AB-OPT, Seo et al., 2009) was used to optimize hourly SAC-parameters and estimate empirical 1-h UH.

\subsubsection{Distributed SAC-SMA}

The distributed SAC-SMA model (Koren et al., 2004) is a gridded version of the lumped SACSMA model. The distributed SAC-SMA model operates on the so-called Hydrologic Rainfall Analysis Project (HRAP; Reed and Maidment, 1999) grid mesh, which is about 4-km in size and it is also the default grid mesh of NWS radar and multisensor precipitation estimates. Once the runoff at each grid box is calculated as described in Section 2.1.1, the kinematic-wave routing model is used to route the runoff through the hillslopes and channels based on cell-to-cell connectivity (Reed, 2003; Koren et al., 2004). The radar-gauge precipitation data at the scale of the HRAP grid is available for the most part of the US. A priori parameters of the distributed SAC-SMA model 
were estimated from the soil data and the routing parameters were from the digital elevation model (DEM) and channel hydraulic data (Koren et al., 2004). This study used manually-optimized model parameters obtained from Phase 1 of the Distributed Model Intercomparison Project (DMIP, Smith et al. 2004). Depth-specific soil moisture contents can be calculated from the original SAC states by using the soil moisture translation routine of the SAC-HT (Koren et al., 2006, 2014), or the SACSMA with heat transfer dynamics.

\subsection{Hydrologic data assimilation problem}

The specific DA problem solved in this study may be stated as follows. Given the a priori model soil moisture states, streamflow observations at the outlet and observed precipitation $(\mathrm{P})$ and monthly climatology of potential evapotranspiration (PE), update the model soil moisture states at the beginning of the assimilation window and multiplicative biases in P and PE. The above DA problem may be solved by applying the model as a strong constraint to the problem, i.e., the error in the model itself is not considered when solving the DA problem (Sasaki, 1970; Zupanski, 1997; Di Lorenzo et al., 2007). Alternatively, the model error can be formulated and solved together with model states by treating the model as a weak constraint to the problem. Below, we formulate the above problem using a WC DA approach which can be easily converted to a SC DA formulation by 
ignoring the model error terms. The DA problem described above can be formulated as the following nonlinear constrained least-squares minimization problem:

\section{Minimize}

$$
\begin{aligned}
J_{K}\left(\mathbf{X}_{S, K-L}, \mathbf{X}_{P}, \mathbf{X}_{E}, \mathbf{X}_{W}\right)=\frac{1}{2}\left[\mathbf{Z}_{B}-\mathbf{H}_{B} \mathbf{X}_{S, K-L}\right]^{T} \mathbf{R}_{B}^{-1}\left[\mathbf{Z}_{B}-\mathbf{H}_{B} \mathbf{X}_{S, K-L}\right] \\
+\frac{1}{2}\left[\mathbf{Z}_{P}-\mathbf{H}_{P} \mathbf{X}_{P}\right]^{T} \mathbf{R}_{P}^{-1}\left[\mathbf{Z}_{P}-\mathbf{H}_{P} \mathbf{X}_{P}\right] \\
+\frac{1}{2}\left[\mathbf{Z}_{E}-\mathbf{H}_{E} \mathbf{X}_{E}\right]^{T} \mathbf{R}_{E}^{-1}\left[\mathbf{Z}_{E}-\mathbf{H}_{E} \mathbf{X}_{E}\right] \\
+\frac{1}{2}\left[\mathbf{Z}_{Q}-\mathbf{H}_{Q}\left(\mathbf{X}_{S, K-L}, \mathbf{X}_{P}, \mathbf{X}_{E}, \mathbf{X}_{W}\right)\right]^{T} \mathbf{R}_{Q}^{-1}\left[\mathbf{Z}_{Q}-\mathbf{H}_{Q}\left(\mathbf{X}_{S, K-L}, \mathbf{X}_{P}, \mathbf{X}_{E}, \mathbf{X}_{W}\right)\right] \\
+\frac{1}{2} \mathbf{X}_{W}^{T} \mathbf{R}_{W}^{-1} \mathbf{X}_{W}
\end{aligned}
$$

In the above, $\mathrm{J}_{\mathrm{K}}$ denotes the objective function value at hour $\mathrm{K} ; \mathbf{X}_{\mathrm{S}}$ denotes the state vector of the SAC-SMA model, or UZTWC, UZFWC, LZTWC, LZFSC, LZFPC, and ADIMC (Table 1); $\mathbf{X}_{\mathrm{P}}$ and $\mathbf{X}_{\mathrm{E}}$ denote the multiplicative adjustment factors for the precipitation and PE data at $\mathrm{k}=\mathrm{K}-\mathrm{L}+1$, $\ldots, \mathrm{K}$, respectively, within the assimilation window; the subscript $\mathrm{k}$ denotes the time index; $\mathrm{X}_{\mathrm{S}, \mathrm{j}, \mathrm{i}}{ }^{\min }$ and $\mathrm{X}_{\mathrm{S}, \mathrm{j}, \mathrm{i}}{ }^{\max }$ denote the lower and upper bounds of the $\mathrm{j}$-th state variable at the $\mathrm{i}$-th grid, $\mathrm{X}_{\mathrm{S}, \mathrm{j}, \mathrm{i}} ; \mathrm{n}_{\mathrm{S}}$ denotes the number of SAC states $\left(n_{S}=6\right.$ in this study for both distributed and lumped SAC-SMA); 
$\mathrm{n}_{\mathrm{C}}$ denotes the number of HRAP cells within the basin in the case of distributed modeling, or $\mathrm{n}_{\mathrm{C}}=1$ in the case of lumped modeling; L denotes the length of the assimilation window - the duration of unit hydrograph is used for $\mathrm{L}$ which represents the time scale of the fast response of the basin (Table 2); $\mathbf{M}\left(\right.$ ) denotes the SAC-SMA model; $\mathbf{H}_{\mathrm{P}}, \mathbf{H}_{\mathrm{E}}, \mathbf{H}_{\mathrm{B}}$, and $\mathbf{H}_{\mathrm{Q}}$ ( ) denote the observation operators that relate the control vector $\left(\mathbf{X}_{\mathrm{P}}, \mathbf{X}_{\mathrm{E}}, \mathbf{X}_{\mathrm{S}, \mathrm{K}-\mathrm{L}}\right.$, and $\left.\mathbf{X}_{\mathrm{W}}\right)$ to observations $\left(\mathbf{Z}_{\mathrm{P}}, \mathbf{Z}_{\mathrm{E}}, \mathbf{Z}_{\mathrm{B}}\right.$, and $\left.\mathbf{Z}_{\mathrm{Q}}\right)$ where, in this study, $\mathbf{H}_{\mathrm{P}}=\mathbf{Z}_{\mathrm{P}}, \mathbf{H}_{\mathrm{E}}=\mathbf{Z}_{\mathrm{E}}, \mathbf{H}_{\mathrm{B}}=\mathbf{I}$, and $\mathbf{H}_{\mathrm{Q}}(\mathrm{)}$ is the distributed SAC-SMA and kinematicwave routing models in Subsection 2.2.1, or the lumped SAC-SMA and unit hydrograph models in Subsection 2.2.2; $\mathbf{R}_{\mathrm{P}}, \mathbf{R}_{\mathrm{E}}, \mathbf{R}_{\mathrm{B}}, \mathbf{R}_{\mathrm{Q}}$ and $\mathbf{R}_{\mathrm{W}}$ denote the measurement error covariance matrices for precipitation, PE, background model state, streamflow, and the model error, respectively; $\mathbf{Z}_{\mathrm{P}}, \mathbf{Z}_{\mathrm{E}}$, and $\mathbf{Z}_{\mathrm{Q}}$ denote the observations of precipitation, $\mathrm{PE}$, and streamflow at $\mathrm{k}=\mathrm{K}-\mathrm{L}+1, \ldots, \mathrm{K}$, respectively; $\mathbf{Z}_{\mathrm{B}}$ denotes the model states at $\mathrm{k}=\mathrm{K}-\mathrm{L}$, i.e., the beginning of the assimilation window. In this work, we set $\mathbf{Z}_{\mathrm{B}}$ equal to the value of the a priori $\mathbf{X}_{\mathrm{S}, \mathrm{K}-\mathrm{L}}$ due to lack of soil moisture observations. The objective function, Eq.(1), is based on the following observation equations:

$$
\begin{aligned}
& \mathbf{Z}_{\mathrm{Q}}=\mathbf{H}_{\mathrm{Q}}\left(\mathbf{X}_{\mathrm{S}, \mathrm{K}-\mathrm{L}}, \mathbf{X}_{\mathrm{P}}, \mathbf{X}_{\mathrm{E}}, \mathbf{X}_{\mathrm{W}}\right)+\mathbf{V}_{\mathrm{Q}} \\
& \mathbf{Z}_{\mathrm{P}}=\mathbf{H}_{\mathrm{P}} \mathbf{X}_{\mathrm{P}}+\mathbf{V}_{\mathrm{P}} \\
& \mathbf{Z}_{\mathrm{E}}=\mathbf{H}_{\mathrm{E}} \mathbf{X}_{\mathrm{E}}+\mathbf{V}_{\mathrm{E}} \\
& \mathbf{Z}_{\mathrm{B}}=\mathbf{H}_{\mathrm{B}} \mathbf{X}_{\mathrm{S}, \mathrm{K}-\mathrm{L}}+\mathbf{V}_{\mathrm{B}}
\end{aligned}
$$


In the above, $\mathbf{V}_{\mathrm{Q}}, \mathbf{V}_{\mathrm{P}}, \mathbf{V}_{\mathrm{E}}, \mathbf{V}_{\mathrm{B}}$, and $\mathbf{V}_{\mathrm{W}}$ denote measurement error vectors for streamflow, P, PE, background model states, and the rainfall-runoff model error. The $\mathbf{Z}_{\mathrm{W}}$ denotes (unknown) observations of an error in the rainfall-runoff model. The gist of the WC DA approach lies at the use of Xw. Similarly to Eq. (1) in Beven (2005), the rainfall-runoff model error $\mathbf{X}_{\mathrm{W}}$ may relate to runoff observations $\left(\mathbf{Z}_{\mathrm{R}}\right)$ by Eq. (8).

$\mathbf{Z}_{\mathrm{R}}+\mathbf{V}_{\mathrm{R}}=\mathbf{M}_{\mathrm{R}}\left(\mathbf{X}_{\mathrm{S}, \mathrm{K}-\mathrm{L}}, \mathbf{X}_{\mathrm{P}}, \mathbf{X}_{\mathrm{E}}\right)+\mathbf{X}_{\mathrm{W}}$

In Eq. (8), $\mathbf{V}_{\mathrm{R}}$ denotes the measurement error vector for runoff and $\mathbf{M}_{\mathrm{R}}$ represents the rainfallrunoff model. Note in Eq. (8) that, in order to model the error in a rainfall-runoff model, $\mathbf{X}_{\mathrm{W}}$ is added to the model-generated runoff $\mathbf{M}_{R}$ - to reflect this into the model source code, the code can be modified by adding $\mathbf{X}_{\mathrm{W}}$ to the model generated runoff, set aside including the $\mathbf{X}_{\mathrm{W}}$ term in the objective function, Eq. (1). Since control variables are the only variables adjusted or updated via DA, $\mathbf{M}_{R}$ is presented as a function of $\mathbf{X}_{\mathrm{S}, \mathrm{K}-\mathrm{L}}, \mathbf{X}_{\mathrm{P}}$, and $\mathbf{X}_{\mathrm{E}}$ in Eq. (8). Theoretically, however, $\mathbf{M}_{\mathrm{R}}$ should also be a function of model parameters, space-time resolutions, etc. In this respect, $\mathbf{X}_{\mathrm{W}}$ can be interpreted as an agglomerated error of all unresolved error sources propagated by fluxes through 
model dynamics to the point of generating runoff. If a systematic model bias exists in reproducing streamflow, this may be reflected in the long-term mean $\mathbf{X}_{\mathrm{W}}$ of a large positive or negative value. Eq. (8) may be separately written for slow and fast responding runoff components, or collectively for the total channel inflow (TCI). Other important considerations include how to specify the spacetime structure of $\mathbf{X}_{\mathrm{W}}$ and its error statistics. When solving the objective function J in Eq. (1), $\mathbf{X}_{\mathrm{W}}$ is initially assumed zero, i.e., no error in the rainfall-runoff transformation processes; during the minimization, $\mathbf{X}_{\mathrm{W}}$ is changed based on the gradient of $\mathbf{J}$ with respect to $\mathbf{X}_{\mathrm{W}}$ in a way to minimize $\mathbf{J}$. Adding $\mathbf{X}_{\mathrm{W}}$ to the runoff is equivalent to adding uncertainties to the initial conditions of the routing model. If the routing model is perfect, differences in streamflow generated from WC DA and SC DA will tell the sole benefit of modeling rainfall-runoff model errors on streamflow. Since routing models are not error-free in reality, the difference may signify the amount of improvement achievable in the presence of routing model errors; this leaves a room to improvement attainable via routing error modeling in addition to rainfall-runoff model error modeling - a topic left for a future effort. Fig. 1 shows a schematic of control variables, including $\mathbf{X}_{\mathrm{W}}$, to be adjusted or updated by the assimilation procedure for rainfall-runoff and routing models. Since the SC DA approach does not account for the model error, the SC DA problem can be formulated by omitting the $\mathbf{X}_{\mathrm{W}}$ terms from the WC formulation, i.e., Eqs. (1) to (8). Examples of the SC and WC formulations for both distributed and lumped SAC-SMA models are presented in Tables 3 and 4, as described in 
Subsections 2.2.1 and 2.2.2. To solve Eqs. (1) and (2), we use VAR which can handle nonlinear observation equations typically associated with assimilation of streamflow observations and provide full-rank solutions, as opposed to ensemble Kalman filter (Evensen, 1994) which is optimal for linear observation equations only and provides reduced-rank solutions only. As a fix-lag smoother, VAR can readily account for the basin response time of fast runoff which is important to effectively capture the time-lagged effect of soil moisture to streamflow. Compared to particle filters (Gordon et al., 1993), VAR is not subject to the curse of dimensionality (Rebeschini and van Handel, 2015) and requires much less computing resources, and hence is suitable for the real-time operational environment.

\subsubsection{WC DA formulation for the distributed SAC-SMA}

Given the spatiotemporal variations expected in the goodness of hydrologic models, one may expect significant inter-pixel variability of the model error. Its assessment requires spatially heterogeneous modeling of $\mathbf{X}_{\mathrm{W}}$ which greatly increases the dimensionality of the state space. On the other hand, if pixel-to-pixel variability of the model error is marginal, spatially homogeneous modeling of $\mathbf{X}_{\mathrm{W}}$ should be preferred, which greatly reduces the size of the control vector. This study comparatively evaluates spatially heterogeneous vs. homogeneous $\mathrm{X}_{\mathrm{W}}$. In both cases, $\mathbf{X}_{\mathrm{W}}$ is allowed to vary at an hourly time step within the assimilation window. To investigate differences in the 
magnitude of the model errors associated with slow and fast runoff components, $\mathbf{X}_{\mathrm{W}}$ is applied separately to surface $\left(\mathbf{X}_{W}^{S U R F}\right)$ and ground $\left(\mathbf{X}_{W}^{G R N D}\right)$ water runoff components. To constrain the DA problem to the rainfall-runoff dynamics of the model only, biases in the forcing data were not estimated via DA by excluding the forcing error terms from the objective function. This forces the DA procedure to solve for the errors associated with runoff generation components by adjusting $\mathbf{X}_{W}^{S U R F}$ and $\mathbf{X}_{W}^{G R N D}$. Eq. (7) can be re-written as Eqs. (9) and (10) for $\mathbf{X}_{W}^{S U R F}$ and $\mathbf{X}_{W}^{G R N D}$, respectively:

$$
\begin{aligned}
& \mathbf{Z}_{W}^{\text {SURF }}=\mathbf{H}_{W}^{\text {SURF }}\left(\mathbf{X}_{S, K-L}, \mathbf{X}_{W}^{S U R F}\right)+\mathbf{V}_{W}^{S U R F} \\
& \mathbf{Z}_{W}^{G R N D}=\mathbf{H}_{W}^{G R N D}\left(\mathbf{X}_{S, K-L}, \mathbf{X}_{W}^{G R N D}\right)+\mathbf{V}_{W}^{G R N D}
\end{aligned}
$$

In the SAC-SMA model, the total runoff is given by the sum of the surface and groundwater runoffs which were modified by adding the model error terms, as described in the right hand side of Eq. (8), which results in Eqs. (12) and (13), respectively:

$$
\begin{aligned}
& \operatorname{TCI}_{k, i}\left(\mathbf{x}_{S, K-L}\right)=\operatorname{SURF}_{k, i}\left(\mathbf{x}_{S, K-L}\right)+\operatorname{GRND}_{k, i}\left(\mathbf{x}_{S, K-L}\right) \\
& \operatorname{SURF}_{k, i}\left(\mathbf{x}_{S, K-L}\right)=\operatorname{ROIMP}_{k, i}\left(\mathbf{X}_{S, K-L}\right)+\operatorname{SDRO}_{k, i}\left(\mathbf{x}_{S, K-L}\right)+\operatorname{SSUR} R_{k, i}\left(\mathbf{X}_{S, K-L}\right)+X_{W, k, i}^{S U R F} \\
& \operatorname{GRND}_{k, i}\left(\mathbf{X}_{S, K-L}\right)=\operatorname{SIF}_{k, i}\left(\mathbf{x}_{S, K-L}\right)+B F C C_{k, i}\left(\mathbf{x}_{S, K-L}\right)+X_{W, k, i}^{G R N D}
\end{aligned}
$$


where the subscripts $\mathrm{k}$ and i represent the k-th time step and the i-th HRAP grid, respectively; TCI, SURF, GRND, ROIMP, SDRO, SSUR, SIF, and BFCC represent the total channel inflow, total surface runoff, total ground runoff, impervious area runoff, direct runoff, surface runoff, interflow, and base flow, respectively; and $X_{W, k, i}^{S U R F}$ and $X_{W, k, i}^{G R N D}$ represent the errors in surface and ground runoff at the k-th time step at the i-th HRAP grid, respectively.

Due to lack of information and for simplicity, we assume in this study that the observational errors are time-invariant and independent of one another (see Lee et al. (2011) and Seo et al. (2003) for justification). With this assumption, the observation error covariance matrices, $\mathbf{R}_{\mathrm{B}}, \mathbf{R}_{\mathrm{Q}}$ and $\mathbf{R}_{\mathrm{W}}$, in Eq. (1) become diagonal and static. The spatiotemporal structure and statistical properties of the observation errors in $\mathbf{Z}_{W}^{S U R F}$ and $\mathbf{Z}_{W}^{G R N D}$ are not known in reality. As a practical approximation, it is assumed in this work that the above observations are non-informative which drops the last term in the right hand side of Eq. (1). As a result, $X_{W, k, i}^{S U R F}$ and $X_{W, k, i}^{G R N D}$ are freely adjusted within the modeldynamical constraint. Based on the above, Eqs. (1) and (2) can be rewritten as Eqs. (14) and (15):

\section{Minimize}

$$
\begin{aligned}
& J_{K}\left(\mathbf{X}_{S, K-L}, \mathbf{X}_{W}\right)=\frac{1}{2} \sum_{k=K-L+1}^{K}\left[Z_{Q, k}-H_{Q, k}\left(\mathbf{X}_{S, K-L}, \mathbf{X}_{W}\right)\right]^{2} \sigma_{Q}^{-2} \\
& +\frac{1}{2} \sum_{j=1}^{n_{S}} \sum_{i=1}^{n_{C}}\left[Z_{B, j, i, K-L}-X_{S, j, i, K-L}\right]^{2} \sigma_{B, j}^{-2}
\end{aligned}
$$

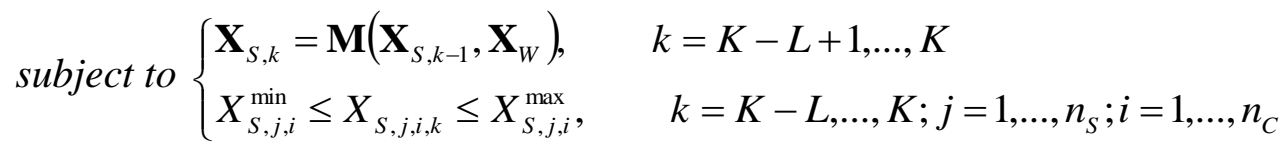


In the above, $\mathrm{Z}_{\mathrm{Q}, \mathrm{k}}$ denotes the streamflow observation at the basin outlet valid at hour $\mathrm{k} ; \mathrm{Z}_{\mathrm{B}, \mathrm{j}, \mathrm{i}, \mathrm{K}-\mathrm{L}}$ denotes the background model state associated with the $\mathrm{j}$-th state variable at the $\mathrm{i}$-th HRAP grid box at the beginning of the assimilation window; $\mathrm{H}_{\mathrm{Q}, \mathrm{k}}($ ) denotes the observation operator that maps $\mathbf{X}_{\mathrm{S}, \mathrm{K}-\mathrm{L}}$ to streamflow at hour $\mathrm{k} ; \sigma_{\mathrm{Q}}$ denotes the standard deviation of the streamflow observation error at the basin outlet; $\sigma_{\mathrm{B}, \mathrm{j}}$ denotes the standard deviation of the error associated with the $\mathrm{j}$-th background (i.e., a priori) model state.

The above constrained minimization problem is solved numerically using the Fletcher-ReevesPolak-Ribiere (FRPRMN) algorithm (Press et al., 1992), a conjugate gradient method. The gradient of the objective function with respect to the control vector is evaluated using the adjoint code generated from Tapenade (http://tapenade.inria.fr:8080/tapenade/index.jsp). Table 3 summarizes variables and equations used for WC and SC DA for the distributed SAC-SMA model. The results from the distributed modeling case study are summarized in Subsection 3.1.

\subsubsection{WC DA formulation for the lumped SAC-SMA}

For lumped modeling, we adopted a simpler approach to describe model errors than in the distributed modeling example described in the previous section. The objective was to investigate the effects of keeping the dimensionality of the control variable space of lumped modeling low on 
WC DA results. Instead of separately modeling errors in surface and ground flow, $\mathbf{X}_{\mathrm{W}}$ is directly added to TCI, assuming time-invariant $\mathbf{X}_{\mathrm{W}}$ at the storm scale. The above description of $\mathbf{X}_{\mathrm{W}}$ is based on results obtained from Seo et al. (2009), who applied the WC-only DA approach to headwater basins in TX. In this work, we focus on comparatively evaluating WC DA against SC DA. The observation equation for $\mathbf{X}_{\mathrm{W}}$ is shown in Eq.(16) and Eq.(17) shows how TCI and $\mathrm{X}_{\mathrm{W}}$ are related:

$$
\begin{aligned}
& \mathbf{Z}_{W}=\mathbf{H}_{W}\left(\mathbf{X}_{S, K-L}, \mathbf{X}_{P}, \mathbf{X}_{E}, \mathbf{X}_{W}\right)+\mathbf{V}_{W} \\
& \operatorname{TCI}\left(\mathbf{X}_{S, K-L}, \mathbf{X}_{P}, \mathbf{X}_{E}\right)=\operatorname{SURF}\left(\mathbf{X}_{S, K-L}, \mathbf{X}_{P}, \mathbf{X}_{E}\right)+\operatorname{GRND}\left(\mathbf{X}_{S, K-L}, \mathbf{X}_{P}, \mathbf{X}_{E}\right)+X_{W}
\end{aligned}
$$

Similarly to the distributed modeling case in Subsection 2.2.1, we assumed time-invariance and independence of observational errors which render $\mathbf{R}_{\mathrm{P}}, \mathbf{R}_{\mathrm{E}}, \mathbf{R}_{\mathrm{B}}$, and $\mathbf{R}_{\mathrm{Q}}$ in Eq. (1) diagonal and static. Following Seo et al. (2003, 2009), $\mathbf{Z}_{\mathrm{B}}$ in Eq. (1) is assumed non-informative which drops the first term in the right hand side of Eq. (1). Eqs. (1) and (2) can then be rewritten as:

\section{Minimize}




$$
\begin{aligned}
J_{K}\left(\mathbf{X}_{S, K-L}, \mathbf{X}_{P}, \mathbf{X}_{E}, \mathbf{X}_{W}\right)=\frac{1}{2} & \sum_{k=K-L+1}^{K}\left[Z_{Q, k}-H_{Q, k}\left(\mathbf{X}_{S, K-L}, \mathbf{X}_{P}, \mathbf{X}_{E}, \mathbf{X}_{W}\right)\right]^{2} \sigma_{Q}^{-2} \\
& +\frac{1}{2} \sum_{k=K-L+1}^{K} Z_{P, k}^{2}\left[1-X_{P, k}\right]^{2} \sigma_{P}^{-2} \\
& +\frac{1}{2} \sum_{k=K-L+1}^{K} Z_{P E, k}^{2}\left[1-X_{E, k}\right]^{2} \sigma_{E}^{-2} \\
& +\frac{1}{2} \sum_{k=K-L+1}^{K} X_{W, k}{ }^{2} \sigma_{W}^{-2}
\end{aligned}
$$

subject to $\left\{\begin{array}{l}\mathbf{X}_{S, k}=\mathbf{M}\left(\mathbf{X}_{S, k-1}, \mathbf{X}_{P}, \mathbf{X}_{E}, \mathbf{X}_{W}\right), \quad k=K-L+1, \ldots, K \\ X_{S, j}^{\min } \leq X_{S, j, k} \leq X_{S, j}^{\max }, \quad k=K-L, \ldots, K ; j=1, \ldots, n_{S}\end{array}\right.$

In the above, $\mathrm{Z}_{\mathrm{Q}, \mathrm{k}}$ denotes the streamflow observation at hour $\mathrm{k} ; \mathrm{H}_{\mathrm{Q}, \mathrm{k}}(\mathrm{)}$ ) denotes the observation operator that maps $\mathbf{X}_{\mathrm{S}, \mathrm{K}-\mathrm{L}}$ to streamflow at hour k; $\sigma_{\mathrm{Q}}$ denotes the standard deviation of the outlet flow observation error; $\sigma_{\mathrm{P}}$ and $\sigma_{\mathrm{E}}$ represent the standard deviation of the error in precipitation and PE data, respectively. The time-invariance assumption of $\mathbf{X}_{\mathrm{W}}$ simplifies the last term in the right hand side of Eq. (18) to $\frac{L}{2} X_{W}{ }^{2} \sigma_{W}^{-2}$ where $\sigma_{\mathrm{W}}$ denotes the standard deviation of the model error and is modeled as in Eq. (20) based on the experimental DA operation at West Gulf River Forecast Center in Texas (Seo et al., 2009):

$$
\sigma_{W}=\sqrt{10^{-10 \exp \left(-Z_{Q, k} / 10\right)}}
$$

As in the distributed modeling case, the minimization problem in Eqs. (18) and (19) is solved by using the FRPRMN algorithm (Press et al., 1992) and the gradients are evaluated using adjoint 
code from Tapenade (http://tapenade.inria.fr:8080/tapenade/index.jsp). Table 4 summarizes the settings used for WC and SC DA for the lumped SAC-SMA model. Results from the lumped modeling case study are summarized in Subsection 3.2.

\subsection{Study area}

For distributed modeling DA, the study area used is the TIFM7 basin which is a $2258 \mathrm{~km}^{2}$ headwater catchment that drains into the Elk River near Tiff city, MO (Fig. 2; Table 2). The basin has the annual precipitation of $1117 \mathrm{~mm}$ and runoff of $246 \mathrm{~mm}$. The basin elevation varies from 229 to $457 \mathrm{~m}$ and soil types are silty clay (39.8\%), silty clay loam (30.5\%), and silt loam (25.8\%) (Smith et al., 2004). Two United States Geological Survey (USGS) stream gauges are available at Lanagan and Powell within the basin and have the drainage area of 619 , and $365 \mathrm{~km}^{2}$, respectively. Hourly streamflow observations are available for TIFM7 from Oct 1992 to July 2002 and, for Lanagan and Powell, from May 2000 to July 2002. The data from Oct 1992 through Apr 2000 was used for model spin-up, and May 2000 through July 2002 for the data assimilation experiments.

For lumped modeling DA, the study area includes nineteen basins in Texas within the service area of the West Gulf River Forecast Center (WGRFC) which have drainage areas of 137 to 1981 $\mathrm{km}^{2}$ (Table 2). Basins located in eastern Texas are wetter than those in western Texas based on 
runoff coefficients and Bowen ratio (Reed et al. 1997). Runoff coefficients of most basins vary from 0.08 to 0.39 except that GBHT2 and HBMT2 show runoff coefficients of 0.68 and 0.95 , respectively, due to the high level of urbanization around Houston, TX (Liscum, 2001). Mean annual precipitation varies from 537 to $1437 \mathrm{~mm}$. Hourly streamflow data were obtained from the USGS.

\subsection{Evaluation metrics}

SAC states (Table 1) and depth-specific soil moisture converted from SAC states (Koren et al., 2014) were evaluated based on mean absolute difference (MAD; Eq. (21)), correlation coefficient ( $\gamma$; Eq. (22)), or a variant of fast Earth Mover's Distance (EMD; Eq. (23) and (24); Pele and

Werman, 2008) between a priori and updated values.

$M A D=\frac{\sum_{k=1}^{T}\left|X_{s, j, k}^{-}-X_{s, j, k}^{+}\right|}{T}$

$\gamma=\sqrt{\frac{\sum_{k=1}^{T}\left(X_{s, j, k}^{-}-\bar{X}_{s, j, k}^{-}\right)\left(X_{s, j, k}^{+}-\bar{X}_{s, j, k}^{+}\right)}{\sqrt{\sum_{k=1}^{T}\left(X_{s, j, k}^{-}-\bar{X}_{s, j, k}^{-}\right)^{2}} \sqrt{\sum_{k=1}^{T}\left(X_{s, j, k}^{+}-\bar{X}_{s, j, k}^{+}\right)^{2}}}}$

where, $X_{S, j, k}^{-}$and $X_{S, j, k}^{+}$denote a priori or updated j-th SAC state at hour $k$, respectively. In the case of distributed modeling, MAD and $\gamma$ were evaluated for an individual grid. In addition, spatial correlation coefficients were calculated using SAC states or soil moisture from all grids at a 
particular hour k.

The EMD was used to quantify the spatial similarity of a priori and updated SAC states or depth-specific soil moisture. The EMD by Pele and Werman (2008) was divided by total flow in order to calculate the ground distance, as in the original EMD (Rubner et al., 2000). Equations and (24) show the EMD used in this work.

$\operatorname{EMD}(P, Q)=\frac{\left(\min _{\left\{f_{i j}\right\}} \sum_{i, j} f_{i j} d_{i j}\right)+\left|\sum_{i} P_{i}-\sum_{j} Q_{j}\right| \max _{i, j}\left\{d_{i j}\right\}}{\min _{\left\{f_{i j}\right\}} \sum_{i, j} f_{i j}}$

subject to $\sum_{j} f_{i j} \leq P_{i}, \quad \sum_{i} f_{i j} \leq Q_{j}, \quad \sum_{i, j} f_{i j} \leq \min \left(\sum_{i} P_{i}, \sum_{j} Q_{j}\right), \quad f_{i j} \geq 0$

In the above, $\mathrm{f}_{\mathrm{ij}}$ denotes flows, or the amount of mass of states or soil moisture transported from an i-th bin of a histogram P (or, i-th HRAP grid of a spatial field P) to a j-th bin of the other histogram Q (or, j-th HRAP grid of a spatial field Q); $d_{i j}$ represents the ground distance between i-th and $\mathrm{j}$-th bins of two histograms, or i-th and j-th HRAP grids of a priori and updated spatial fields. The EMD finds flows $\mathrm{f}_{\mathrm{ij}}$ between two spatial fields, $\mathrm{P}$ and $\mathrm{Q}$, that minimize $\sum_{i, j} f_{i j} d_{i j}$. In Eq. (23), $\left|\sum_{i} P_{i}-\sum_{j} Q_{j}\right| \max _{i, j}\left\{d_{i j}\right\}$ considers a difference in the total mass between P and Q. In this work, total number of HRAP grids was used as total number of bins in order to calculate flows separately for 
individual pixels.

The root-mean-square-error (RMSE) was used to evaluate streamflow analysis and prediction.

Streamflow analysis was generated with updated states and observed precipitation within the assimilation window. To produce streamflow prediction, we used updated states at the end of the assimilation window as initial conditions for the prediction window and observed precipitation as a proxy of precipitation forecasts in order to simplify DA problems and assess performance gains achievable with highly accurate precipitation forecasts.

$R M S E=\sqrt{\frac{\sum_{k=1}^{T}\left(Z_{Q, k}-H_{Q, k}\right)^{2}}{T}}$

where $\mathrm{Z}_{\mathrm{Q}, \mathrm{k}}$ and $\mathrm{H}_{\mathrm{Q}, \mathrm{k}}$ denote observed or modeled streamflow at hour $k$, respectively, and $\mathrm{T}$ denotes the total number of time steps.

Timing errors (TE) in simulated streamflow were estimated based on the phase difference of observed and simulated hydrographs computed by a wavelet-based technique (Liu et al., 2011).

$T E=\frac{\tau}{2 \pi} \tan ^{-1}\left(\frac{\left.\mathfrak{I}\left(\left\langle s^{-1} W_{n}^{X Y}(s)\right\rangle\right)\right)}{\mathfrak{R}\left(\left\langle s^{-1} W_{n}^{X Y}(s)\right\rangle\right)}\right)$ 
where $\tau$ denotes the equivalent Fourier period of the wavelet; $W_{n}^{X Y}(s)$ represents the cross wavelet spectrum of two time series $X$ and $Y ; n$ and $s$ denote the location and scale parameter of the wavelet, respectively; $\mathfrak{I}()$ and $\mathfrak{R}()$ denote the imaginary and real parts of the variable in the bracket, respectively; \langle\rangle denotes the smoothing operation in both time and frequency domains. Eq. (26) calculates the TE in hr. The positive (negative) TE means observed hydrograph trailing (leading) simulated hydrograph.

\section{Case study}

This section describes results from applying a WC DA approach to two different modeling cases, distributed or lumped, in comparison to those from a SC DA approach.

\subsection{Case 1: Distributed modeling}

This section summarizes results from applying the distributed SAC-SMA model to the TIFM7 basin (Fig. 2) for the period of May, 2000 through July, 2002 (Table 2). For $\mathbf{X}_{\mathrm{W}}$ modeling, two types of spatial structure of $\mathbf{X}_{\mathrm{W}}$ were tested, either spatially homogeneous or heterogeneous. Spatially heterogeneous $\mathbf{X}_{\mathrm{W}}$ modeling provides a freedom or flexibility to independently model errors in runoff components at individual pixels. Without increasing the size of observations to help infer the 
spatial structure of $\mathbf{X}_{\mathrm{W}}$, however, its increased dimensionality of control variables could diminish the potential benefit of heterogeneous $\mathbf{X}_{\mathrm{W}}$ modeling. Results from spatially homogeneous $\mathbf{X}_{\mathrm{W}}$ modeling will be comparatively evaluated with those from spatially heterogeneous $\mathbf{X}_{\mathrm{W}}$ modeling in order to gain understanding on the necessary level of $\mathbf{X}_{\mathrm{W}}$ modeling in terms of its spatial structure in the case of assimilating outlet flow-only. Evaluation of DA results was focused on the amount of adjustment made to a priori state variables and base model-generated streamflow posterior to the assimilation, which was examined in terms of magnitude and correlation from three different aspects, i.e., variabilities at a pixel scale (Figs. 3 and 4; Tables 5 and 6), the preservation of water balance (Table 7), and spatial similarity of a priori and updated state variables (Fig. 5; Table 8).

At a pixel- or HRAP-scale, spatially homogeneous $\mathbf{X}_{\mathrm{W}}$ modeling generally less adjusts state variables or soil moisture than heterogeneous $\mathbf{X}_{\mathrm{W}}$ modeling in terms of both MAD and $\gamma$ (Table 5; Figs. 3 and 4), indicating potentially spatially correlated model errors and/or benefits of solving less under-determined DA problem. It should be noted that, while small in magnitude, homogeneous adjustment over the catchment has a large impact on water balance. The effects of heterogeneous adjustment, on the other hand, cancel out due to spatial random averaging over the catchment area. Pixels neighbouring the outlet were adjusted more than the rest (Figs. 3 and 4) partially because outlet flow observations contain more relevant information on the dynamics at those pixels than far upstream pixels, given their shorter geographical distances to the assimilation location. On the 
contrary, information contained in the flow delivered from far upstream locations to the outlet may be too largely diluted for the assimilation procedure to properly adjust model states at those locations, resulting in smaller MAD and higher $\gamma$ at upstream locations (Figs. 3 and 4). Spatially homogeneous $\mathbf{X}_{\mathrm{W}}$ modeling reduces basin mean MAD of SAC states by 37-88 \% against SC DA results whereas heterogeneous $\mathbf{X}_{\mathrm{W}}$ modeling reduces the MAD by $37-75 \%$ (Table 5). Contrary to results on SAC states, the reduction range of the MAD for soil moisture profile is narrow, i.e., 50$54 \%$ and $62-67 \%$ in the case of SC and WC DA, respectively (Table 5). Among six SAC states updated via WC DA, LZFSC showed the least percentage reduction range (37-39\% in reference to SC DA results) in terms of MAD (Table 5) possibly due to largely altering correlation structure of a priori LZFSC by the DA (Fig. 4). In the case of SC DA, both LZTWC and LZFPC showed larger MAD than other SAC states (Fig. 3). Although WC DA produced noticeably smaller MAD of a priori and updated LZTWC and LZFPC than SC DA results (Table 5), the MADs posterior to WC DA for the two states are still relatively larger than MADs for other SAC states (Fig. 3). This may indicate a room to improve the accuracy of model parameters associated with evapotranspiration or low flows such that LZTWC and LZFPC do not compensate for parametric errors.

In Table 6, the spatial correlation of a priori and updated surface soil moisture at 5 and $25 \mathrm{~cm}$ depths is generally higher than 0.99 for both SC and WC DA cases. While SC DA somewhat reduces the spatial correlation of a priori and updated soil moisture at 60,75 and $100 \mathrm{~cm}$ depths, 
spatially homogeneous $\mathbf{X}_{\mathrm{W}}$ modeling restores the spatial correlation up to 0.99 (Table 6). Among six states, the spatial correlation structure of a priori UZFWC is most seriously broken (0.64) via the SC DA which is recovered up to 0.75 via the homogeneous $\mathrm{Xw}$ modeling. The similar applies to LZFSC, i.e., $\gamma=0.88$ or 0.97 in the case of SC DA or WC DA with homogeneous $\mathbf{X}$ w modeling, respectively (Table 6).

The WC DA produced basin-mean state variables closer to a priori states than the SC DA, resulting in smaller MAD between a priori and updated basin-mean SAC states in the case of WC DA than SC DA results. For instance, the basin-mean LZFSC via the WC DA with heterogeneous or homogeneous $\mathrm{Xw}$ modeling is about 7 or $23 \%$, respectively, closer to a priori LZFSC than SC DA results in terms of MAD (Table 7). Temporal correlation coefficients of a priori and updated basin-mean state variables are all bigger than 0.99 and the difference between WC and SC DA results are marginal.

The EMD between two (a priori vs. updated) spatial fields indicated larger spatial dissimilarities for deep ( $\geq 60 \mathrm{~cm}$ ) soil moisture as well as free water contents (FWCs, i.e., UZFWC, LZFSC and LZFPC) at both subsurface storages (UZ and LZ) (Fig. 5). Given the large role of FWCs on producing fast-responding runoff components and its spatial similarity with rainfall spatial variability, favourably adjusting FWCs by the assimilation procedure may result in larger distortion in its spatial structure than TWCs. Particularly, the SC DA distorts the spatial similarities 
of LZFSC about 10 times larger than the WC DA with homogeneous $\mathrm{X}_{\mathrm{W}}$ modeling. For all SAC states and depth-specific soil moisture contents, the homogeneous $\mathbf{X}_{\mathrm{W}}$ modeling yields the most similar spatial fields to the a priori ones in terms of EMD (Fig. 5 \& Table 8).

Fig. 6 shows the maps of temporal mean $\mathbf{X}_{W}^{S U R F}$ and $\mathbf{X}_{W}^{G R N D}$ evaluated at the HRAP scale separately for the two $\mathbf{X}_{\mathrm{W}}$ modeling cases. Spatially homogeneous $\mathbf{X}_{\mathrm{W}}$ modeling produced larger mean $\mathbf{X}_{W}^{S U R F}$ and $\mathbf{X}_{W}^{G R N D}$ than the heterogeneous $\mathbf{X}_{\mathrm{W}}$ case by about 2 and 19 times, respectively. The smaller adjustment to runoff in the case of heterogeneous $\mathbf{X}_{\mathrm{W}}$ modeling, particularly for upstream pixels, may be because outlet flow observations may not provide relevant information to upstream locations (see discussions given for Figs. 3 and 4 above). In addition, the problem is largely illposed due to the elevated level of under-determinedness by modeling $\mathbf{X}_{\mathrm{W}}$ in a distributed way which renders the DA procedure passive in adjusting runoff. Streamflow results indicated that the WC DA improves RMSE of outlet flow analysis and prediction (Fig. 7) with less adjustment to state variables and soil moisture, compared to the case of SC DA (Tables 5 to 7; Figs. 3 to 5).

\subsection{Case 2: Lumped modeling}

The lumped SAC-SMA model was applied to nineteen basins in Texas (Fig. 2) and the simulation period for each basin is summarized at Table 2. The WC DA produces generally smaller 
MAD and higher $\gamma$ for all SAC states and depth-specific soil moisture than the SC DA (Figs. 8 and 9). Among six SAC states, LZTWC benefited the most largely from the WC approach in terms of multi-basin mean of MAD (23 and 7 (mm) in the case of SC or WC DA, respectively; Fig. 8). LZFPC shows relatively larger multi-basin mean MAD than other states in the case of SC DA (e.g., $10(\mathrm{~mm})$ in Fig. 8) but WC DA resolved the MAD of LZFPC by $36 \%$ only, the smallest MAD reduction among six SAC states analysed (Table 9). As found similar results in the distributed modeling case study summarized in Section 3.1, large multi-basin mean MAD for LZTWC and LZFPC in both cases of SC and WC DA may indicate poorly calibrated parameters associated with evapotranspiration or low flows that may be compensated by overly adjusting relevant states, i.e., LZTWC and LZFPC, via DA.

In the case of free water content (FWC), the SC DA tends to over-adjust its temporal correlation structure particularly in the LZ, i.e., LZFSC and LZFPC (Table 9 \& Fig. 9); WC DA results also show generally lower correlation of a priori and updated LZFSC or LZFPC than other states (Fig. 9). Since FWCs respond to atmospheric forcing faster than TWCs during the event, adjusting FWCs necessarily entail modifying its temporal correlation structure largely than TWCs. On the other hand, the SC DA modifies a priori ADIMC larger than FWCs in terms of MAD (Fig. 8) while less breaking its correlation structure (Fig. 9). This may be because the creation and disappearance of FWCs relies on the occurrence of precipitation events more than the impervious 
area flow.

Fig. 10 shows the temporal mean of $\mathbf{X}_{\mathrm{W}}$ (circle) and $\left|\mathbf{X}_{\mathrm{W}}\right|$ (dot) for the entire assimilation period. The mean $\mathbf{X}_{\mathrm{W}}$ of non-zero indicates that systematic biases in simulated runoff exist and vary basin to basin. The large inter-basin variability of mean $\left|\mathbf{X}_{\mathrm{W}}\right|$ indicates that, even with the same model applied to all basins, the estimates of model structural inadequacies differ (e.g., up to 10 times based on Fig. 10) due to different basin physiographic, hydrologic properties as well as the different quality of calibrated parameters. For instance, GBHT2 and HBMT2 are characterised as fast-responding, highly urbanized basins with time to peak of 5 and $3 \mathrm{~h}$ and runoff coefficients of 0.64 and 0.94 , respectively (Seo et al., 2009; Lee et al., 2012). Without properly accounting for urban storm drainage network within the lumped modeling framework, large water balance model errors may exist in the simulated runoff for GBHT2 and HBMT2, as indicated in Fig. 10.

Though marginal, the WC DA generally produces smaller RMSE of streamflow analysis and prediction than the SC DA (Fig. 11), i.e., multi-basin mean RMSE of streamflow analysis and prediction for the entire simulation period (Table 2) is 2.4 and $4.9\left(\mathrm{~m}^{3} / \mathrm{sec}\right)$ in the case of WC DA but 2.7 and $5.3\left(\mathrm{~m}^{3} / \mathrm{sec}\right)$ in the case of SC DA.

\section{Discussions}

In this section, we further describe and discuss WC DA results for the distributed SAC-SMA 
model in the case of biased forcing data used, and similarities found in both lumped and distributed SAC-SMA model results with assimilation. Also, discussed are model error structures, various effects of WC DA on assimilation results, accounting for routing model errors within a WC DA framework, and issues associated with verifying WC DA results.

To address biases in the forcing data in the case of distributed modeling, forcing error modeling should be carefully designed to pose the assimilation problem less ill-posed given the already large dimensionality of the state-space. From the viewpoint of WC DA, correcting forcing errors is expected to whiten or reduce the residual errors to be modeled via $\mathbf{X}_{\mathrm{W}}$. As an example, including a bias correction term (in the form of hourly varying mean field bias, Lee and Seo, 2014) for both precipitation and potential evaporation in the objective function (Eq. (14)) resulted in reduced adjustment to both $\mathbf{X}_{W}^{S U R F}$ and $\mathbf{X}_{W}^{G R N D}$, compared to Fig. 6; for instance, in the case of spatially homogeneous $\mathbf{X}_{\mathrm{W}}$ modeling, $\mathbf{X}_{W}^{S U R F}$ and $\mathbf{X}_{W}^{G R N D}$ were reduced from 0.03 to 0.02 , and from 4.89 to 2.43 , respectively; in the case of heterogeneous $\mathrm{X}_{\mathrm{W}}$ modeling, basin-mean $\mathbf{X}_{W}^{S U R F}$ and $\mathbf{X}_{W}^{G R N D}$ were reduced from 0.018 to 0.015 , and from 0.26 to 0.18 , respectively. Although forcing error modeling reduces the amount of residual errors tackled via $\mathbf{X}_{\mathrm{W}}$, impact of modeling forcing errors on updated state variables may need separate attentions due to the increased under-determinedness of the assimilation problem - left for a future effort. For snow-dominated basins, similar effects may be expected by accounting for a bias in the temperature data. 
Albeit differences in control variables, objective functions and model specifics, lumped and distributed SAC-SMA produced similar assimilation results in that updated LZTWC and LZFPC are largely different from a priori ones in both cases of SC and WC DA. This may be attributed to either poorly calibrated parameters associated with low flows or evapotranspiration or poor descriptions of the relevant processes within both models' domain. To investigate the effect of the latter on WC DA results, similar DA experiments can be performed with the SAC-SMA with enhanced descriptions on evapotranspiration (Koren et al., 2010), left as a future work.

The form of model errors used in this study is experimental rather than based on a theory or data analysis. As every model is structurally different, model errors from any two models may also be structurally different, e.g., additive vs. multiplicative, normal vs. lognormal, etc. Besides, model errors may be correlated with errors in forcing observations through model dynamics which may require error covariance modeling depending on the degree of correlation between the two (Doherty and Welter, 2010). Along with thorough intensive discussions on the validity of environmental models (Grayson et al., 1992; Beven, 2005; Bredehoeft, 2005; Gupta et al., 2012; Arnold et al., 2015), systematic investigations, under synthetic environments if needed, are also necessary to understand the form and function of model errors (Renard et al., 2010; Schoups and Vrugt., 2010), similarly to the efforts to understand different model structures and their functioning (Clark et al., 2008). For a highly instrumented basin with states and runoff observations available, it may be 
interesting to investigate differences between observations and simulations in states and runoff generated from SC or WC approaches with different forms of $\mathbf{X}_{\mathrm{W}}$.

Effects of accounting for model errors on assimilation results could be multi-dimensional, e.g., less adjusting, less subject to error compensation issues, similar or improved analysis or prediction, error whitening, etc. Different degrees of adjusting different states by both SC and WC DA approaches may illuminate the source of model errors and the reason for the adjustment, e.g., compensating for deficiency in process description. Source-specific error modeling may lead to poor prediction due to error compensation (Kavetski et al., 2003; Beven, 2005). WC approaches used in this study may reduce the risk of being subject to error compensation issues by accounting for overall model errors in addition to source-specific errors. WC DA approaches may also whiten the error in a priori states so that the adverse effect of residual errors in state analysis on the prediction of soil moisture and flow may be minimal.

Routing model errors may be treated separately from water balance model errors that will help solve different types of model errors in a reduced dimension, as opposed to solving errors in the two models with a single error model. Depending on routing techniques, e.g., lumped or cell-to-cell routing, routing model errors may have different properties. Cell-to-cell routing may allow identifying pixel-specific timing errors whereas lumped routing treat them only in a basin-averaged fashion. From upstream to downstream pixels, cell-to-cell routing may integrate errors in water 
balance models into its own errors, requiring the development of a sophisticated routing error modeling technique to treat routing errors separately from water balance model errors. Fig. 12 shows that WC DA approaches without accounting for routing model errors may still reduce noticeably the MAD of flow observations and forecasts for 1-72 lead hours for 105 events from MTPT2 for the period of May 1996 - Mar 2005, but at a cost of overly shifting the entire phase of the hydrograph over the forecast horizon, hence, increasing (wavelet-based estimates of) timing errors (TE; Liu et al., 2011) in flow forecasts more than SC DA in the TE range of -4 to $8 \mathrm{~h}$. On the other hand, when TE is larger, e.g., above 9 or below -9 h, TE as well as MAD is reduced via both SC and WC DA in both rising (Fig. 12a) and recession limbs (Fig. 12b) due possibly to the increased correlation of amplitude and timing errors in the case of a large phase shift in the overall hydrograph along the time axis. In the case of early rising limb (Fig. 12c), TE of WC DA results is larger than the case of the entire rising limb (Fig. 12a), signifying the importance of routing error modeling in WC DA approaches for early accurate detection of flood timing. Future efforts can investigate changes in TE posterior to routing model error modeling via WC DA approaches.

Verification against observations is an important step to confirm the validity of assimilation results. A lack of observations of hydrologic model states for most basins in the world defies the straightforward verification of a priori as well as updated states. Given unavailability of state observations, minimal adjustment to model states by a WC DA approach may be logically 
plausible. If state observations are available, comparison between WC DA and SC DA results should be based on verifying updated states against equivalent observations, rather than against a priori states. This questions the legibility of findings in this work and underscores the importance of model calibration as well as forcing data accuracy in order to derive accurate a priori model states.

\section{Summary and a concluding remark}

This study showed promising results on applying WC DA approaches to rainfall-runoff modeling. Two example applications in the context of lumped and distributed modeling were demonstrated after formulating WC DA problems separately for the lumped and distributed SACSMA models. In the case of the distributed SAC-SMA model, accounting for the rainfall-runoff model error in a spatially homogeneous manner yielded updated states spatially more similar to a priori states than the case of spatially heterogeneous error modeling. For both cases of lumped and distributed SAC-SMA models, assimilating outlet flow using the WC DA approach generally produced smaller MAD as well as higher $\gamma$ of a priori and updated states than the SC DA approach, while producing similar or reduced RMSE of streamflow analysis and prediction. Albeit differences in model structures of lumped and distributed SAC-SMA and DA formulations used, both models showed similar assimilation results in that model states related to evapotranspiration or low flows tended to be over-adjusted, implying potential issues with calibration focused on high flows or 
deficiency in model structures describing relevant processes.

Since models are always defective, WC approaches with appropriate error modeling should generally offer beneficial effects on assimilation results. Given the ambiguousness of error structures associated with individual model and their properties, a parsimonious way of model error modeling may be favoured which still effectively help reduce unintended by-effects of DA on analysis and prediction, as illustrated in this work. Despite omnipresent deficiencies in every single model, a model is still useful for solving real-world problems as long as accompanied with a proper quantification of uncertainties associated with its products. More importantly, a model is a heuristic tool to improve and test our understanding by synthesizing our knowledge and experience into it (Oreskes, 1994; Bredehoeft, 2005). While challenges and questions remain as to how to properly quantify model structural inadequacy and mitigate its impact on assimilation results (Liu and Gupta, 2007; Schaefli et al., 2007; Del Giudice et al., 2015), model error modeling via WC DA approaches may help us understand their sources and effects and offer something advantageous over SC DA approaches.

\section{Acknowledgements}

The $2^{\text {nd }}$ and $3^{\text {rd }}$ co-authors were supported in part by the National Science Foundation under Grants CyberSEES-1442735 (Dong-Jun Seo, University of Texas at Arlington, PI). This support is 
gratefully acknowledged. The program to compute Earth Mover's Distance (EMD) was obtained from http://www.ariel.ac.il/sites/ofirpele/fastemd/code/ (last accessed on June $27^{\text {th }}, 2016$ ) which is gratefully acknowledged. We would like to thank Yuqiong Liu for providing the source code for estimating timing errors with a wavelet-based technique. We are also grateful to the two anonymous reviewers and the associate editor for providing many helpful comments.

\section{References}

Adams, T., Ostrowski, J., 2010, Short lead-time hydrologic ensemble forecasts from numerical weather prediction model ensembles, World Environmental and Water Resources Congress, 2294-2304, doi: 10.1061/41114(371)237.

Arnold, S., Attinger, S., Frank, K., Hildebrandt, A., 2015. Assessing the structural adequacy of alternative ecohydrological models using a pattern-oriented approach. Ecol. Model. 316, 5261. doi:10.1016/j.ecolmodel.2015.08.003.

Beven, K.J., 2005. On the concept of model structural error, Water Science \& Technology, 52(6), 167-175.

Beven, K., 2008. Environmental Modelling: An Uncertain Future?, 1st ed. CRC Press.

Beven, K., Smith, P.J., Wood, A., 2011. On the colour and spin of epistemic error (and what we might do about it). Hydrol. Earth Syst. Sci. 15, 3123-3133. doi:10.5194/hess-15-3123-2011. 
Burnash, R.J., Ferral, R.L., McGuire, R.A., 1973. A generalized streamflow simulation system: conceptual modeling for digital computers. U.S. Department of Commerce National Weather Service and State of California Department of Water Resources.

Bredehoeft, J., 2005. The conceptualization model problem - surprise, Hydrogeol. J., 13, 37-46.

Carpenter, T.M., Georgakakos, K.P., 2004, Impacts of parametric and radar rainfall uncertainty on the ensemble streamflow simulations of a distributed hydrologic model, J. Hydrol. 298(1-4), 202-221.

Cha, S.-H., 2007, Comprehensive survey on distance/similarity measures between probability density functions, Int. J. Math. Model. Methods Appl. Sciences, 1(4), 300-307.

Clark, M.P., Slater, A.G., Rupp, D.E., Woods, R.A., Vrugt, J.A., Gupta, H.V., Wagener, T., Hay, L.E., 2008, Framework for Understanding Structural Errors (FUSE): A modular framework to diagnose differences between hydrological models, Water Resour. Res. 44(12), W00B02, doi:10.1029/2007WR006735.

Del Giudice, D., Reichert, P., Bares, V., Albert, C., Rieckermann, J., 2015. Model bias and complexity - Understanding the effects of structural deficits and input errors on runoff predictions. Environ. Model. Softw. 64, 205-214. doi:10.1016/j.envsoft.2014.11.006.

Di Lorenzo, E., Moore, A.M., Arango, H.G., Cornuelle, B.D., Miller A.J., Powell, B., Chua, B.S., Bennett, A.F., 2007. Weak and strong constraint data assimilation in the inverse Regional 
Ocean Modeling System (ROMS): Development and application for a baroclinic coastal upwelling system, Ocean Model., 16, 160-187.

Doherty, J., Welter, D., 2010. A short exploration of structural noise, Water Resour. Res., 46, W05525, doi:10.1029/2009WR008377.

Eckhardt, K., Breuer, L., Frede, H.-G., 2003, Parameter uncertainty and the significance of simulated land use change effects, J. Hydrol., 273(1-4), 164-176.

Eknes, M., Evensen, G., 1995. Parameter estimation solving a weak constraint variational problem. Proceedings of WMO's $2^{\text {nd }}$ International Symposium on Assimilation of observations in meteorology and oceanography, March 1995. Tokyo, Japan; PWPR report series no. 5; WMO/TD- no. 651; Vol. I, 95-97.

Evensen, G., 1994, Sequential data assimilation with a nonlinear quasi-geostrophic model using Monte Carlo methods to forecast error statistics, J. Geophys. Res., 99(C5), 10,143-10,162. Feyen, L., Vrugt, J.A., Nuallain, B.O., van der Knijff, J., Roo, A.D., 2007, Parameter optimisation and uncertainty assessment for large-scale streamflow simulation with the LISFLOOD model, J. Hydrol., 332, 276-289.

Gordon N.J., Salmond, D.J., Smith, A.F.M., 1993, Novel approach to nonlinear/non-Gaussian Bayesian state estimation, IEE Proc. F., 140, 107-113.

Grayson, R.B., Moore, I.D., McMahon, T.A., 1992. Physically Based Hydrologic Modeling 2. Is the 
Concept Realistic?, Water Resour. Res., 26(10), 2659-2666.

Gupta, H.V., Clark, M.P., Vrugt, J.A., Abramowitz, G., Ye, M., 2012. Towards a comprehensive assessment of model structural adequacy, Water Resour. Res., 48, W08301, doi:10.1029/2011WR011044.

Hawkins, D.M., 2004, The problem of overfitting, J. Chem. Inf. Comput. Sci., 44, 1-12.

Hoeting, J.A., Madigan, D., Raftery, A.E., Volinsky, C.T., 1999, Bayesian model averaging: A tutorial, Stat. Science, 14(4), 382-417.

Kavetski, D., Franks, S, Kuczera, G., 2003, Confronting input uncertainty in environmental modeling. In Calibration of Watershed Models, Duan, Q., Gupta, H., Sorooshian, S., Rousseau, A.N. and Turcotte, R. (eds), AGU Books, Washington, pp. 49-68.

Koren, V., Reed, S., Smith, M., Zhang, Z., Seo, D.-J., 2004. Hydrology laboratory research modeling system (HL-RMS) of the U.S. national weather service. J. Hydrol. 291, 297-318.

Koren, V., Fekadu, M., Reed, S., Smith, M., Zhang, Z., 2006. Evaluation of grid-based distributed hydrological model over a large area. In: Prediction in Ungauged Basins: Promise and Progress (Proc. Of Symposium S7 at Foz do Iguacu, Brazil, April 2005), IAHS Publ. 303, 47-56.

Koren, V., Smith, M., Cui, Z., Cosgrove, B., Werner, K., Zamora, R., 2010. Modification of Sacramento Soil Moisture Accounting Heat Transfer Component (SAC-HT) for Enhanced Evapotranspiration. NOAA Technical Report NWS 53. 
<http://www.nws.noaa.gov/oh/hrl/hsmb/docs/hydrology/PBE_SAC-

SMA/NOAA_Technical_Report_NWS_53.pdf>.

Koren, V., Smith, M., Cui, Z., 2014. Physically-based modifications to the Sacramento Soil

Moisture Accounting model. Part A: Modeling the effects of frozen ground on the runoff generation process. J. Hydrol. 519, 3475-3491.

Kuczera, G., Kavetski, D., Franks, S., Thyer, M., 2006, Towards a Bayesian total error analysis of conceptual rainfall-runoff models: Characterising model error using storm-dependent parameters, J. Hydrol., 331, 161-177.

Lee, H., Seo, D-J., Koren, V., 2011, Assimilation of streamflow and in-situ soil moisture data into operational distributed hydrologic models: Effects of uncertainties in the data and initial model soil moisture states, Adv. Water Resour., 34, 1597-1615.

Lee, H., Seo, D.-J., Liu, Y., Koren, V., McKee, P., Corby, R., 2012, Variational assimilation of streamflow into operational distributed hydrologic models: Effect of spatiotemporal scale of adjustment, Hydrol. Earth Syst. Sci., 16, 2233-2251.

Lee, H., Seo, D.-J., 2014, Assimilation of hydrologic and hydrometeorological data into distributed hydrologic model: Effect of adjusting mean field bias in radar-based precipitation estimates, J. Hydrol., 74, 196-211.

Liscum, F., 2001, Effects of urban development on stormwater runoff characteristics for the 
Houston, Texas, metropolitan area, USGS Water-Resources Investigations Report 01-4071,

U.S. Dept. of the Interior, US Geological Survey, Austin, Texas.

Liu, Y., Gupta, H.V., 2007, Uncertainty in hydrologic modeling: Toward an integrated data assimilation framework, Water Resour. Res., 43, W07401, doi:10.1029/2006WR005756.

Liu, Y., Brown, J., Demargne, J., Seo, D.-J., 2011, A wavelet-based approach to assessing timing errors in hydrologic predictions, J. Hydrol., 397, 210-224.

Michaud, J.D., Sorooshian, S., 1994, Effect of rainfall-sampling errors on simulations of desert flash floods, Water Resour. Res., 30(10), 2765-2775.

Montanari, A., Di Baldassarre, G., 2013, Data errors and hydrological modelling: The role of model structure to propagate observation uncertainty. Adv. Water Resour., 35th Year Anniversary Issue 51, 498-504. doi:10.1016/j.advwatres.2012.09.007

Nash, J.E., 1957, The form of the instantaneous unit hydrograph, Int. Assoc. Sci. Hydrol., Publication, 45(3), 114-121.

Oreskes, N., Shrader-Frechette, K, Belitz, K., 1994, Verification, validation, and confirmation of numerical models in the earth sciences, Science, 263, 641-646.

Palmer, T.N., Alessandri, A., Andersen, U., Cantelaube, P., Davey, M., Delecluse, P., Deque, M., Diez, E., Doblas-Reyes, F.J., Feddersen, H., Graham, R., Gualdi, S., Gueremy, J.-F., Hagedorn, R., Hoshen, M., Keenlyside, N., Latif, M., Lazar, A., Maisonnave, E., Marletto, V., Morse, A.P., 
Orfila, B., Rogel, P, Terres, J.-M., Thomson, M.C., 2004, Development of a European multimodel ensemble system for seasonal-to-interannual prediction (DEMETER), Bull. Amer. Meteor. Soc., 85, 853-872.

Parrish, M.A., Moradkhani, H., DeChant, C.M., 2012, Toward reduction of model uncertainty: Integration of Bayesian model averaging and data assimilation. Water Resour. Res. 48, W03519. doi:10.1029/2011WR011116

Pele, O., Werman, M., 2008, A linear time histogram metric for improved shift matching. In: Forsyth, D., Torr, P., Zisserman, A. (eds.) European Conference on Computer Vision (ECCV) 2008, Part III. LNCS, 5304, pp. 495-508, Springer, Heidelberg (2008).

Press, W.H., Teukolsky, S.A., Vetterling, W.T., Flannery, B.P., 1992, Numerical recipes in fortran, $2^{\text {nd }}$ edition.

Rebeschini, P., van Handel, R., 2015. Can local particle filters beat the curse of dimensionality? Ann. Appl. Probab., 25(5), 2809-2866.

Reed, S. M., D. R. Maidment, and J. Patoux, 1997. Spatial Water Balance of Texas. Center for Research in Water Resources, University of Texas at Austin, CRWR Online Report 97-1 available at http://www.ce.utexas.edu/prof/maidment/gishyd97/library/wbtexas/wbtexas.htm Reed, S.M., Maidment, D.R., 1999. Coordinate transformations for using NEXRAD data in GIS based hydrologic modelling. J. Hydrol. Eng. 4, 174-183. 
Reed, S.M., 2003. Deriving flow directions for coarse-resolution (1-4 km) gridded hydrologic modelling. Water Resour. Res. 39(9), 1238, http://dx.doi.org/10.1029/2003WR001989.

Renard, B., Kavetski, D., Kuczera, G., Thyer, M., Franks, S.W., 2010, Understanding predictive uncertainty in hydrologic modeling: The challenge of identifying input and structural errors, Water Resour. Res., 46, W05521, doi:10.1029/2009WR008328.

Roche, A., Malandain, G., Pennec, X., Ayache, N., 1998, The correlation ratio as a new similarity measure for multimodal image registration, In Medical Image Computing and ComputerAssisted Interventation-MICCAI'98, 1115-1124.

Rubner, Y., Tomasi, C., Guibas, L.J., 2000, The Earth Mover's Distance as a metric for image retrieval, Int. J. Computer Vis., 40(2), 99-121.

Sasaki, Y., 1970, Some basic formalisms in numerical variational analysis, Mon. Wea. Rev., 98(12), $875-883$.

Schaefli, B., Talamba, D.B., Musy, A., 2007, Quantifying hydrological modeling errors through a mixture of normal distributions, J. Hydrol., 332, 303-315.

Schoups, G., Vrugt, J.A., 2010, A formal likelihood function for parameter and predictive inference of hydrologic models with correlated, heteroscedastic, and non-Gaussian errors, Water Resour. Res., 46, W10531, doi:10.1029/2009WR008933.

Schulz, K., Seppelt, R., Zehe, E., Vogel, H.J., Attinger, S., 2006, Importance of spatial structures in 
advancing hydrological sciences, Water Resour. Res., 42, W03S03, doi:10.1029/2005WR004301.

Seo, D.-J., Koren, V., Cajina, N., 2003, Real-time variational assimilation of hydrologic and hydrometeorological data into operational hydrologic forecasting, J. Hydrometeorol., 4, $627-641$.

Seo, D.-J., Cajina, L., Corby, R., Howieson, T., 2009, Automatic state updating for operational streamflow forecasting via variational data assimilation, J. Hydrol., 367, 255-275.

Smith, M.B., Seo, D.-J., Koren, V.I., Reed, S.M., Zhang, Z., Duan, Q., Moreda, F., Cong, S., 2004. The distributed model intercomparison project (DMIP): motivation and experiment design. J. Hydrol. 298, 4-26.

Uboldi, F., Kamachi, M., 2000, Time-space weak-constraint data assimilation for nonlinear models, Tellus, 52A, 412-421.

van Andel, S.J., Weerts, A., Schaake, J., Bogner, K., 2013, Post-processing hydrological ensemble predictions intercomparison experiment, Hydrol. Process. 27, 158-161.

Wealands, S.R., Grayson, R.B., Walker, J.P., 2005, Quantitative comparison of spatial fields for hydrological model assessment - some promising approaches, Adv. Water Resour., 28, 15-32. Zhang, Z., Koren, V., Reed, S., Smith, M., Zhang, Y., Moreda, F., Cosgrove, B., 2012, SAC-SMA a priori parameter differences and their impact on distributed hydrologic model simulations, J. 
Hydrol., 420-421, 216-227.

Zupanski, D., 1997, A general weak constraint applicable to operational 4DVAR data assimilation systems, Mon. Wea. Rev., 125, 2274-2292. 
Table 1. Model states updated via VAR for both lumped and distributed SAC-SMA SAC-SMA model states Description

UZTWC Upper Zone Tension Water Content

UZFWC

Upper Zone Free Water Content

LZTWC

Lower Zone Tension Water Content

LZPFC

Lower Zone Primary Free Water Content

LZSFC

Lower Zone Supplemental Free Water Content

ADIMC

Additional impervious area water content 
Table 2. Study basins

\begin{tabular}{|c|c|c|c|c|c|c|c|c|}
\hline No & $\begin{array}{l}\text { Basin } \\
\text { name }\end{array}$ & $\begin{array}{l}\text { Area } \\
\left(\mathrm{km}^{2}\right)\end{array}$ & USGS ID & $\begin{array}{l}\text { Period of record used } \\
\text { in DA experiments }\end{array}$ & $\begin{array}{c}* \text { Annual } \\
\text { rainfall } \\
(\mathrm{mm})\end{array}$ & $\begin{array}{c}* \text { Annual } \\
\text { runoff } \\
(\mathrm{mm})\end{array}$ & $* \mathrm{C}_{\mathrm{R}}$ & $\begin{array}{l}* * \mathrm{~L} \\
(\mathrm{hr})\end{array}$ \\
\hline \multicolumn{9}{|c|}{ Distributed modeling } \\
\hline \multirow[t]{3}{*}{1} & TIFM7 & 2258 & 7189000 & May 2000-July 2002 & \multirow[t]{3}{*}{1117} & \multirow[t]{3}{*}{246} & \multirow[t]{3}{*}{0.22} & \multirow[t]{3}{*}{60} \\
\hline & LANAG & 619 & 7188885 & May 2000-July 2002 & & & & \\
\hline & POWELL & 365 & 7188653 & May 2000-July 2002 & & & & \\
\hline \multicolumn{9}{|c|}{ Lumped modeling } \\
\hline 1 & ATIT2 & 844 & 08159000 & Jan $2000-$ Dec 2001 & 773 & 110 & 0.14 & 30 \\
\hline 2 & BDAT2 & 870 & 08178880 & Jan $2000-$ Dec 2001 & 822 & 181 & 0.22 & 47 \\
\hline 3 & DCJT2 & 1039 & 08053500 & Jan 1997 - Dec 1998 & 829 & 94 & 0.11 & 80 \\
\hline 4 & GBHT2 & 137 & 08076000 & Jan $2000-$ Dec 2001 & 1301 & 878 & 0.68 & 32 \\
\hline 5 & GETT2 & 334 & 08104900 & Jan $2000-$ Dec 2001 & 763 & 160 & 0.21 & 14 \\
\hline 6 & GNVT2 & 212 & 08017200 & Jan 1997 - Dec 1998 & 977 & 242 & 0.25 & 35 \\
\hline 7 & HBMT2 & 246 & 08075000 & Jan $2002-$ Dec 2003 & 1126 & 1070 & 0.95 & 24 \\
\hline 8 & HNTT2 & 769 & 08165500 & Jan 1999 - Dec 2000 & 755 & 100 & 0.13 & 14 \\
\hline 9 & JTBT2 & 945 & 08079600 & Jan 1998 - Dec 1999 & 537 & 44 & 0.08 & 17 \\
\hline 10 & LYNT2 & 508 & 08110100 & Jan $2002-$ Dec 2003 & 967 & 140 & 0.15 & 75 \\
\hline 11 & MCKT2 & 427 & 08058900 & Jan 2001 - Dec 2002 & 908 & 265 & 0.29 & 41 \\
\hline 12 & MDST2 & 870 & 08065800 & Jan 2001 - Dec 2002 & 1018 & 254 & 0.25 & 50 \\
\hline 13 & MTPT2 & 435 & 08162600 & Jan 1997 - Dec 1998 & 1260 & 381 & 0.3 & 80 \\
\hline 14 & PICT2 & 1178 & 08101000 & Jan 1997 - Dec 1998 & 848 & 104 & 0.12 & 30 \\
\hline 15 & QLAT2 & 197 & 08017300 & Jan $2000-$ Dec 2001 & 921 & 360 & 0.39 & 25 \\
\hline 16 & REFT2 & 1787 & 08189500 & Jan $2000-$ Dec 2001 & 864 & 94 & 0.11 & 102 \\
\hline 17 & SBMT2 & 896 & 08164300 & Jan 1997 - Dec 1998 & 1069 & 198 & 0.19 & 55 \\
\hline 18 & SOLT2 & 1746 & 08041700 & Jan $2000-$ Dec 2001 & 1437 & 251 & 0.17 & 173 \\
\hline 19 & UVAT2 & 1981 & 08190000 & Jan 1997 - Dec 1998 & 665 & 119 & 0.18 & 31 \\
\hline
\end{tabular}

* annual rainfall, runoff and runoff coefficients $\left(\mathrm{C}_{\mathrm{R}}\right)$ were estimated based on long-term average

considered more representative than those based on the period used in DA experiments; periods

used are 1992-2005 for TIFM7, and 1996-2005 for all basins used in lumped modeling DA

experiments.

** L denotes the length of the assimilation window which was estimated based on the duration of

the unit hydrograph 
Table 3. Configuration of DA experiments for the distributed SAC-SMA model (see Section 2.2.1).

Weakly-constrained DA

Strongly-constrained DA model error $\left(\mathbf{X}_{\mathrm{W}}\right)$

State vector $\left(\mathbf{X}_{\mathrm{S}}\right)$

Control vector $(\mathbf{X})$

Total channel

inflow (TCI)

Total surface runoff (SURF)
Rainfall-runoff

$$
\mathbf{X}_{W}^{S U R F}, \mathbf{X}_{W}^{G R N D}
$$

either spatially heterogeneous or

homogeneous

UZTWC, UZFWC, LZTWC,

LZFSC, LZFPC, ADIMC

$\mathbf{X}_{\mathrm{W}}, \mathbf{X}_{\mathrm{S}, \mathrm{K}-\mathrm{L}}$

$$
\begin{aligned}
& \operatorname{TCI}_{k, i}\left(\mathbf{X}_{S, K-L}\right)= \\
& \operatorname{SURF}_{k, i}\left(\mathbf{X}_{S, K-L}\right)+G R N D_{k, i}\left(\mathbf{x}_{S, K-L}\right)
\end{aligned}
$$

Eq. (11)

$$
\begin{aligned}
& \operatorname{SURF}_{k, i}\left(\mathbf{x}_{s, K-L}\right)= \\
& \operatorname{ROIMP}_{k, i}\left(\mathbf{x}_{S, K-L}\right)+\operatorname{SDRO}_{k, i}\left(\mathbf{x}_{S, K-L}\right) \\
& +\operatorname{SSUR}_{k, i}\left(\mathbf{x}_{S, K-L}\right)+X_{W, k, i}^{S U R F}
\end{aligned}
$$

Eq. (12)

Total ground runoff $G R N D_{k, i}\left(\mathbf{x}_{S, K-L}\right)=$ (GRND)
UZTWC, UZFWC, LZTWC, LZFSC, LZFPC, ADIMC

$\mathbf{X}_{\mathrm{S} \text { K-L }}$

$T C I_{k, i}\left(\mathbf{X}_{S, K-L}\right)=$ $S U R F_{k, i}\left(\mathbf{X}_{S, K-L}\right)+G R N D_{k, i}\left(\mathbf{X}_{S, K-L}\right)$
$\operatorname{SURF}_{k, i}\left(\mathbf{X}_{S, K-L}\right)=$ $\operatorname{ROIMP}_{k, i}\left(\mathbf{x}_{S, K-L}\right)+\operatorname{SDRO}_{k, i}\left(\mathbf{x}_{S, K-L}\right)$ $+\operatorname{SSUR}_{k, i}\left(\mathbf{x}_{S, K-L}\right)$

$$
\begin{aligned}
& G R N D_{k, i}\left(\mathbf{X}_{S, K-L}\right)= \\
& \operatorname{SIF}_{k, i}\left(\mathbf{X}_{S, K-L}\right)+B F C C_{k, i}\left(\mathbf{x}_{S, K-L}\right)
\end{aligned}
$$

Eq. (13)

Objective function

$$
\begin{gathered}
\frac{1}{2} \sum_{k=K-L+1}^{K}\left[Z_{Q, k}-H_{Q, k}\left(\mathbf{X}_{S, K-L}, \mathbf{X}_{W}\right)\right]^{2} \sigma_{Q}^{-2} \\
+\frac{1}{2} \sum_{j=1}^{n_{S}} \sum_{i=1}^{n_{C}}\left[Z_{B, j, i, K-L}-X_{S, j, i, K-L}\right]^{2} \sigma_{B, j}^{-2} \\
\text { subject to } \\
\left\{\begin{array}{r}
\mathbf{X}_{S, k}=\mathbf{M}\left(\mathbf{X}_{S, k-1}, \mathbf{X}_{W}\right), k=K-L+1, \ldots, K \\
X_{S, j, i}^{\min } \leq X_{S, j, i, k} \leq X_{S, j, i}^{\max }, k=K-L, \ldots, K \\
j=1, \ldots, n_{S} ; i=1, \ldots, n_{C}
\end{array}\right.
\end{gathered}
$$

Eqs. (14) and (15)

$$
\frac{1}{2} \sum_{k=K-L+1}^{K}\left[Z_{Q, k}-H_{Q, k}\left(\mathbf{X}_{S, K-L}\right)\right]^{2} \sigma_{Q}^{-2}
$$$$
+\frac{1}{2} \sum_{j=1}^{n_{S}} \sum_{i=1}^{n_{C}}\left[Z_{B, j, i, K-L}-X_{S, j, i, K-L}\right]^{2} \sigma_{B, j}^{-2}
$$

subject to

$$
\left\{\begin{array}{r}
\mathbf{X}_{S, k}=\mathbf{M}\left(\mathbf{X}_{S, k-1}\right), k=K-L+1, \ldots, K \\
X_{S, j, i}^{\min } \leq X_{S, j, i, k} \leq X_{S, j, i}^{\max }, k=K-L, \ldots, K \\
j=1, \ldots, n_{S} ; i=1, \ldots, n_{C}
\end{array}\right.
$$


Table 4. Configuration of DA experiments for the lumped SAC-SMA model (see Section 2.2.2).

Weakly-constrained DA

Strongly-constrained DA

Rainfallrunoff model

error $\left(\mathbf{X}_{\mathrm{W}}\right)$

State vector

$\left(\mathbf{X}_{\mathrm{S}}\right)$

$$
\mathrm{X}_{\mathrm{W}}
$$

time-invariant at the storm scale

UZTWC, UZFWC, LZTWC,

LZFSC, LZFPC, ADIMC
UZTWC, UZFWC, LZTWC,

LZFSC, LZFPC, ADIMC

\section{Control vector $(\mathbf{X})$}

$$
\mathbf{X}_{\mathrm{W}}, \mathbf{X}_{\mathrm{S}, \mathrm{K}-\mathrm{L}}, \mathbf{X}_{\mathrm{P}}, \mathbf{X}_{\mathrm{E}}
$$

$$
\mathbf{X}_{\mathrm{S}, \mathrm{K}-\mathrm{L}}, \mathbf{X}_{\mathrm{P}}, \mathbf{X}_{\mathrm{E}}
$$

Total channel inflow (TCI)

$$
\begin{array}{r}
\operatorname{TCI}\left(\mathbf{X}_{S, K-L}, \mathbf{X}_{P}, \mathbf{X}_{E}\right)=\operatorname{SURF}\left(\mathbf{X}_{S, K-L}, \mathbf{X}_{P}, \mathbf{X}_{E}\right) \\
+G R N D\left(\mathbf{X}_{S, K-L}, \mathbf{X}_{P}, \mathbf{X}_{E}\right)+X_{W}
\end{array}
$$

$$
\begin{aligned}
\operatorname{TCI}\left(\mathbf{x}_{S, K-L}, \mathbf{X}_{P}, \mathbf{X}_{E}\right)=\operatorname{SURF}\left(\mathbf{x}_{S, K-L}, \mathbf{X}_{P}, \mathbf{X}_{E}\right) \\
+G R N D\left(\mathbf{x}_{S, K-L}, \mathbf{X}_{P}, \mathbf{X}_{E}\right)
\end{aligned}
$$

Eq. (17)

Objective function $(\mathrm{J})$

$$
\begin{array}{lrl}
\frac{1}{2} \sum_{k=K-L+1}^{K}\left[Z_{Q, k}-H_{Q, k}\left(\mathbf{X}_{S, K-L}, \mathbf{X}_{P}, \mathbf{X}_{E}, \mathbf{X}_{W}\right)\right]^{2} \sigma_{Q}^{-2} & \frac{1}{2} \sum_{k=K-L+1}^{K}\left[Z_{Q, k}-H_{Q, k}\left(\mathbf{X}_{S, K-L}, \mathbf{X}_{P}, \mathbf{X}_{E}, \mathbf{X}_{W}\right)\right]^{2} \sigma_{Q}^{-2} \\
+\frac{1}{2} \sum_{k=K-L+1}^{K} Z_{P, k}^{2}\left[1-X_{P, k}\right]^{2} \sigma_{P}^{-2} & & +\frac{1}{2} \sum_{k=K-L+1}^{K} Z_{P, k}^{2}\left[1-X_{P, k}\right]^{2} \sigma_{P}^{-2} \\
+\frac{1}{2} \sum_{k=K-L+1}^{K} Z_{P E, k}^{2}\left[1-X_{E, k}\right]^{2} \sigma_{E}^{-2} & & +\frac{1}{2} \sum_{k=K-L+1}^{K} Z_{P E, k}^{2}\left[1-X_{E, k}\right]^{2} \sigma_{E}^{-2} \\
+\frac{1}{2} \sum_{k=K-L+1}^{K} X_{W, k}{ }^{2} \sigma_{W}^{-2} &
\end{array}
$$

$$
\left\{\begin{array}{c}
\text { subject to } \\
\mathbf{X}_{S, k}=\mathbf{M}\left(\mathbf{X}_{S, k-1}, \mathbf{X}_{P}, \mathbf{X}_{E}, \mathbf{X}_{W}\right), k=K-L+1, \ldots, K \\
X_{S, j}^{\min } \leq X_{S, j, k} \leq X_{S, j}^{\max }, k=K-L, \ldots, K \\
j=1, \ldots, n_{S}
\end{array}\right.
$$

subject to

$$
\left\{\begin{array}{c}
\mathbf{X}_{s, k}=\mathbf{M}\left(\mathbf{X}_{S, k-1}, \mathbf{X}_{P}, \mathbf{X}_{E}\right), k=K-L+1, \ldots, K \\
X_{S, j}^{\min } \leq X_{S, j, k} \leq X_{S, j}^{\max }, k=K-L, \ldots, K \\
j=1, \ldots, n_{S}
\end{array}\right.
$$

Eqs. (18) and (19) 
Table 5. Percentage reduction in mean absolute difference (MAD) as well as correlation coefficient

$(\gamma)$ of a priori and updated model states and soil moisture via WC DA over SC DA in the case of distributed SAC-SMA model. The MAD and $\gamma$ in the table are the basin means of HRAP-scale MAD and $\gamma$ calculated using time series of a priori and updated SAC states or soil moisture at individual HRAP grid. The subscripts D, L and S represent distributed or lumped $\mathbf{X}_{\mathrm{W}}$ modeling, or SC DA.

\begin{tabular}{lcccc}
\hline & $\left(\frac{M A D_{S}-M A D_{D}}{M A D_{S}}\right) \times 100\left(\frac{M A D_{S}-M A D_{L}}{M A D_{S}}\right) \times 100$ & $\left(\frac{\gamma_{D}-\gamma_{S}}{\gamma_{S}}\right) \times 100$ & $\left(\frac{\gamma_{L}-\gamma_{S}}{\gamma_{S}}\right) \times 100$ \\
\hline SAC-SMA model states & & & \\
UZTWC & 75 & 88 & 0.004 & 0.006 \\
UZFWC & 37 & 53 & 0.409 & 0.506 \\
LZTWC & 63 & 80 & 0.154 & 0.194 \\
LZFSC & 39 & 37 & 3.555 & 3.936 \\
LZFPC & 55 & 58 & 0.648 & 0.853 \\
ADIMC & 42 & 67 & 0.005 & 0.014 \\
& & & & \\
Soil moisture & & & 0.011 & 0.014 \\
$5 \mathrm{~cm}$ & 50 & 67 & 0.07 & 0.088 \\
$25 \mathrm{~cm}$ & 52 & 62 & 0.31 & 0.374 \\
$60 \mathrm{~cm}$ & 54 & 62 & 0.31 & 0.374 \\
$75 \mathrm{~cm}$ & 54 & 62 & 0.31 & 0.374 \\
$100 \mathrm{~cm}$ & 54 & 62 & & \\
\hline
\end{tabular}


Table 6. Temporal mean of spatial correlation coefficient $(\gamma)$ of HRAP-scale values in the case of distributed SAC-SMA.

\begin{tabular}{cccc}
\hline \multirow{2}{*}{$\begin{array}{c}\text { SAC-SMA model } \\
\text { states }\end{array}$} & \multicolumn{2}{c}{ Temporal mean of spatial correlation coefficient } \\
\cline { 2 - 4 } & SC DA & $\begin{array}{c}\text { WC DA with } \\
\text { heterogeneous } \mathbf{X}_{\mathrm{W}} \\
\text { modeling }\end{array}$ & $\begin{array}{c}\text { WC DA with } \\
\text { homogeneous } \mathbf{X}_{\mathrm{W}} \\
\text { modeling }\end{array}$ \\
\hline $\begin{array}{c}\text { SAC-SMA model states } \\
\text { UZTWC }\end{array}$ & 0.99 & 0.99 & 0.99 \\
UZFWC & 0.64 & 0.73 & 0.75 \\
LZTWC & 0.98 & 0.99 & 0.99 \\
LZFSC & 0.88 & 0.95 & 0.97 \\
LZFPC & 0.98 & 0.99 & 0.99 \\
ADIMC & 0.99 & 0.99 & 0.99 \\
& & & \\
Soil moisture & 0.99 & 0.99 & 0.99 \\
$5 \mathrm{~cm}$ & 0.99 & 0.99 & 0.99 \\
$25 \mathrm{~cm}$ & 0.96 & 0.98 & 0.99 \\
$60 \mathrm{~cm}$ & 0.96 & 0.98 & 0.99 \\
$75 \mathrm{~cm}$ & 0.96 & 0.98 & 0.99 \\
$100 \mathrm{~cm}$ & & & \\
\hline
\end{tabular}


Table 7. Water balance component analysis using basin-mean SAC states. Temporal correlation coefficients $(\gamma)$ of basin-mean a priori and updated model states are all above 0.99 for D, L, and S where the subscripts D, L and S represent spatially heterogeneous or homogeneous $\mathbf{X}_{\mathrm{W}}$ modeling, or SC DA, respectively.

\begin{tabular}{|c|c|c|c|c|c|c|c|}
\hline & $\left(\frac{M A D_{S}-M A D_{D}}{M A D_{S}}\right.$ & $\times 100$ & $\frac{M A D_{S}-M A D_{L}}{M A D_{S}}$ & $\times 100$ & $\frac{\gamma_{D}-\gamma_{S}}{\gamma_{S}}$ & $\times 100$ & $\left(\frac{\gamma_{L}-\gamma_{S}}{\gamma_{S}}\right) \times 100$ \\
\hline \multicolumn{8}{|c|}{ SAC-SMA model states } \\
\hline UZTWC & 1 & & 1 & & 0.000 & & 0.00011 \\
\hline UZFWC & 4 & & 5 & & -0.00 & 024 & 0.00001 \\
\hline LZTWC & 1 & & 1 & & 0.000 & 08 & -0.00004 \\
\hline LZFSC & 7 & & 23 & & 0.000 & 45 & 0.00184 \\
\hline LZFPC & 1 & & 2 & & -0.00 & & -0.00055 \\
\hline ADIMC & 1 & & 1 & & -0.00 & 005 & 0.00001 \\
\hline
\end{tabular}


Table 8. Analysis of spatial similarity between a priori and updated model states where Earth

Mover's Distance (EMD; Eqs. (23) and (24)) is used to measure the similarity where the subscripts

$\mathrm{D}, \mathrm{L}$ and $\mathrm{S}$ represent spatially heterogeneous or homogeneous $\mathbf{X}_{\mathrm{W}}$ modeling, or SC DA, respectively.

\begin{tabular}{ccc}
\hline & $\left(\frac{E M D_{S}-E M D_{D}}{E M D_{S}}\right) \times 100$ & $\left(\frac{E M D_{S}-E M D_{L}}{E M D_{S}}\right) \times 100$ \\
\hline SAC-SMA model states & 81 & \\
UZTWC & 40 & 62 \\
UZFWC & 64 & 65 \\
LZTWC & 83 & 90 \\
LZFSC & 64 & 67 \\
LZFPC & 44 & 75 \\
ADIMC & & \\
Soil moisture & & 72 \\
$5 \mathrm{~cm}$ & 53 & 63 \\
$25 \mathrm{~cm}$ & 52 & 65 \\
$60 \mathrm{~cm}$ & 56 & 65 \\
$75 \mathrm{~cm}$ & 56 & 65 \\
$100 \mathrm{~cm}$ & 56 & \\
\hline
\end{tabular}


Table 9. Multi-basin mean of percentage reduction in mean absolute difference (MAD) as well as correlation coefficient $(\gamma)$ of a priori and updated model states via WC DA over SC DA in the case of the lumped SAC-SMA model where ${ }^{-}$denotes the multi-basin mean.

\begin{tabular}{ccccc}
\hline $\begin{array}{c}\text { SAC-SMA } \\
\text { model } \\
\text { states }\end{array}$ & $\overline{M A D_{S}}-\overline{M A D_{W}}$ & $\overline{\left(\frac{M A D_{S}-M A D_{W}}{M A D_{S}}\right) \times 100}$ & $\overline{\gamma_{W}}-\overline{\gamma_{S}}$ & $\overline{\left(\frac{\gamma_{W}-\gamma_{S}}{\gamma_{S}}\right) \times 100}$ \\
\hline UZTWC & 1.3 & 89 & 0.04 & 6 \\
UZFWC & 0.2 & 63 & 0.14 & 20 \\
LZTWC & 16.3 & 69 & 0.27 & 64 \\
LZFSC & 0.6 & 48 & 0.3 & 85 \\
LZFPC & 2.8 & 36 & 0.2 & 12 \\
ADIMC & 8.6 & 64 & 0.1 & \\
\hline
\end{tabular}




\section{Figure captions}

Fig. 1. A schematic showing, in generality, the sequence of rainfall-runoff and routing model implementation (solid boxes in the right) and the works carried out by the assimilation procedure (dotted boxes in the left). A WC DA approach includes $\mathbf{X}_{\mathrm{W}, \mathrm{RR}}$ and $\mathbf{X}_{\mathrm{W}, \mathrm{ROUT}}$ (shaded boxes) in the control vector whereas a SC DA approach is not. The control vector of the WC DA approach used in this study does not include $\mathbf{X}_{\mathrm{PAR}, \mathrm{RR}}, \mathbf{X}_{\mathrm{PAR}, \mathrm{ROUT}}$, and $\mathbf{X}_{\mathrm{W}, \mathrm{ROUT}}$ for the sake of formulating simpler WC DA problem as an introductory work in this direction.

Fig. 2. Nineteen basins in Texas used in the lumped modeling and the TIFM7 basin used in the distributed modeling DA experiments. The HRAP grid mesh is laid over the TIFM7 basin boundary map. Details on study basins are found at Table 2 .

Fig. 3. Top: mean absolute difference (MAD) of a priori and updated SAC-SMA model states; bottom: the same as top plots but for soil moisture translated from the model states in the top plots.

Fig. 4. Top: correlation coefficient of a priori and updated SAC-SMA model states; bottom: the same as top plots but for soil moisture translated from the model states in the top plots. 
Fig. 5. Earth Mover's Distance (EMD) for the spatial field of SAC-SMA model states (top) and depth-specific soil moisture (bottom). The EMD of two spatial fields generated from base model and assimilation results is calculated on an hourly time step and averaged over the entire simulation period. At the bottom plot, EMDs for soil moisture fields were calculated for 5 different soil depths measured from the ground surface, i.e., 5, 25, 60, 75, and $100 \mathrm{~cm}$.

Fig. 6. Map of temporal mean $\mathbf{X}_{W}^{S U R F}$ and $\mathbf{X}_{W}^{G R N D}$ generated via WC DA applied to the distributed SAC-SMA.

Fig. 7. RMSE of flow analysis (top) and prediction averaged over 1-6 h lead time (bottom).

Fig. 8. Mean absolute difference (MAD) of a priori and updated SAC states generated via SC (S) and WC (W) data assimilation approach applied to the lumped SAC-SMA. Left plot shows MAD for an individual basin and box plots in the right show multi-basin mean MAD.

Fig. 9. Correlation coefficient $(\gamma)$ of a priori and updated SAC states generated via SC (S) and WC (W) data assimilation approach applied to the lumped SAC-SMA. Left plot shows $\gamma$ for an 
individual basin and box plots in the right show multi-basin mean $\gamma$.

Fig. 10. Long-term mean of $\mathbf{X}_{\mathrm{W}}$ (circle) and $\left|\mathbf{X}_{\mathrm{W}}\right|$ (dot) generated via the WC data assimilation approach applied to the lumped SAC-SMA. Left plot shows $\mathbf{X}_{\mathrm{W}}$ and $\left|\mathbf{X}_{\mathrm{W}}\right|$ for an individual basin and the box plot in the right shows multi-basin mean of $\mathbf{X}_{\mathrm{W}}$ and $\left|\mathbf{X}_{\mathrm{W}}\right|$.

Fig. 11. RMSE of flow analysis (top) and prediction averaged over 1-6 $\mathrm{h}$ lead time (bottom).

Fig. 12. Mean difference in the wavelet-based estimates of timing errors (TE; Liu et al., 2011) or mean absolute value (MAD) of 1-72 h flow forecasts with or without DA, i.e., $\frac{1}{T} \sum_{k=1}^{T}\left(\left|T E_{n o D A, k}\right|-\left|T E_{D A, k}\right|\right)$ or $\frac{1}{T} \sum_{k=1}^{T}\left(M A D_{n o D A, k}-M A D_{D A, k}\right)$ where $\mathrm{k}$ denotes the time index, T represents the number of assimilation cycles, and TE and MAD were evaluated against observed flows. The metrics were calculated separately for 22 different ranges of TE where 20 bins with a 1 -hr interval were used for $-10 \mathrm{~h} \leq \mathrm{TE} \leq 10 \mathrm{~h}, 1$ bin for TE $>10$ $\mathrm{h}$, and 1 bin for TE $<-10 \mathrm{~h}$. The data used is from 105 events from the MTPT2 basin for the period of May 1996 - Mar 2005: (a) rising limb, (b) recession limb, and (c) early rising limb. 


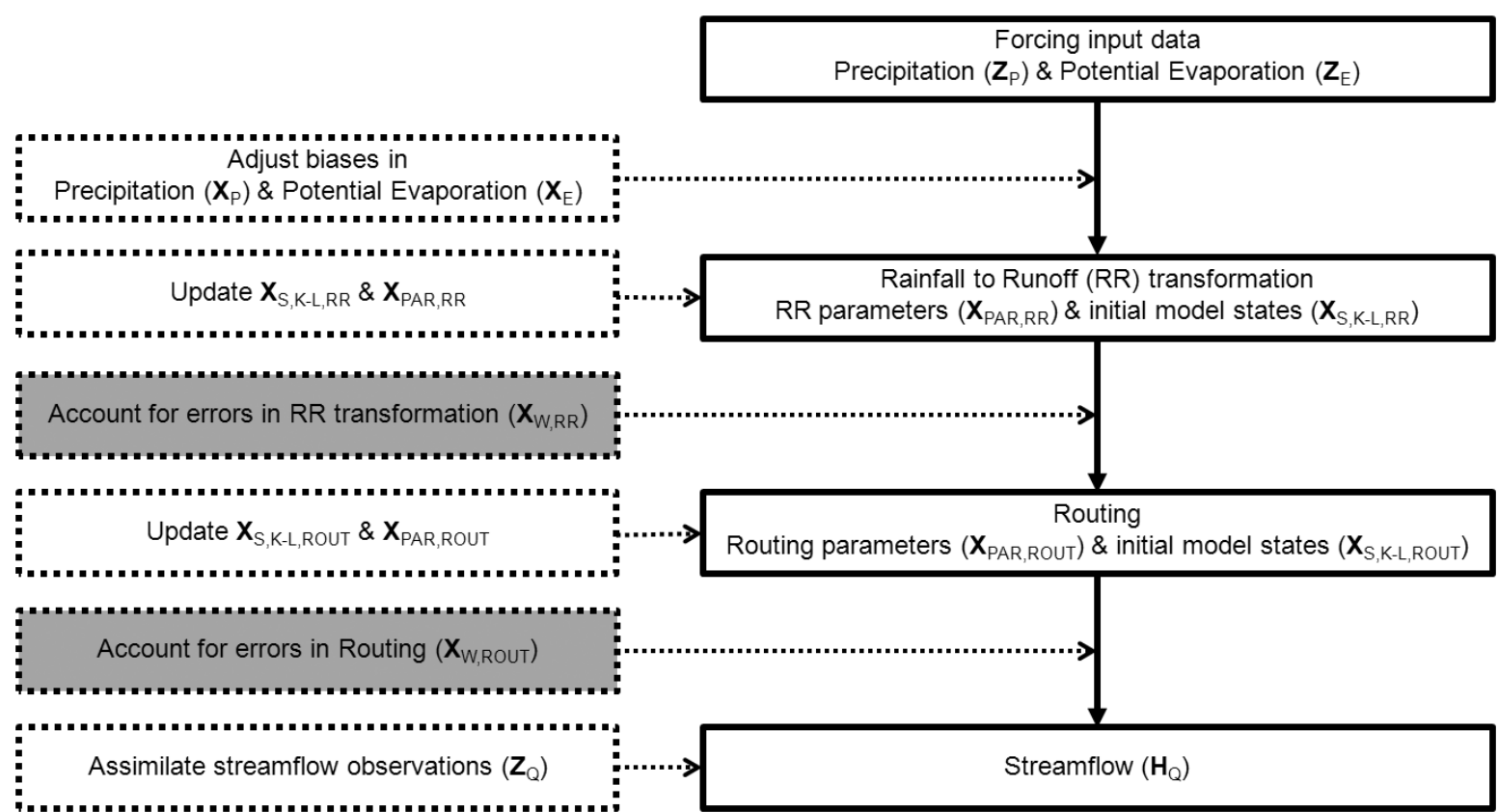



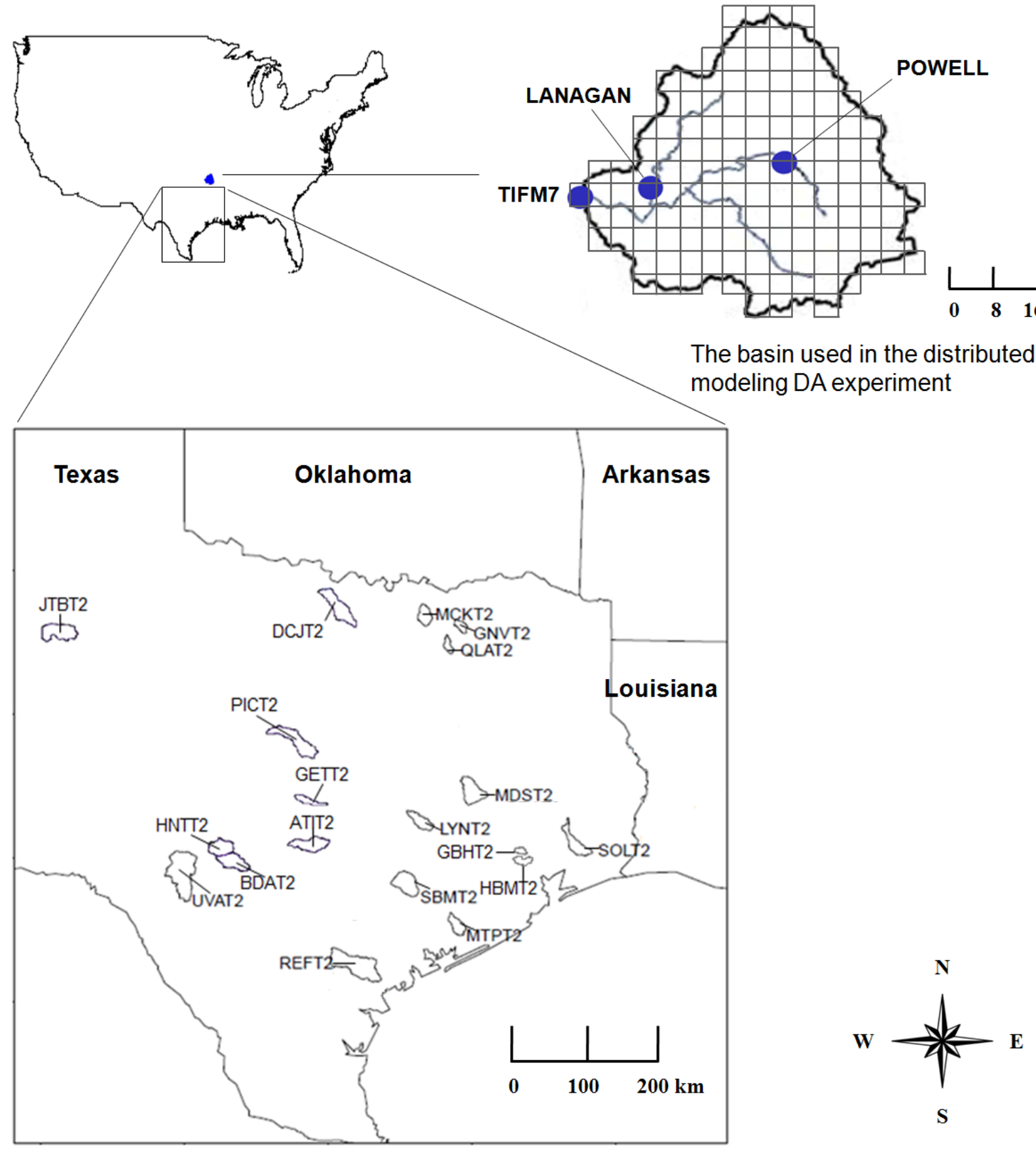

19 basins in Texas used in the lumped modeling DA experiment 
Mean absolute difference of base and updated SAC-SMA model states

UZTWC
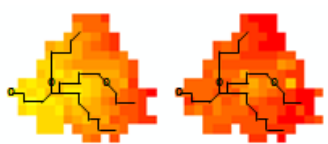

UZFWC

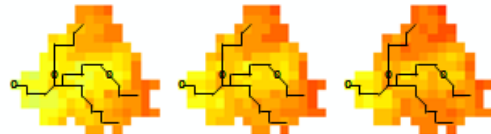

LZTWC

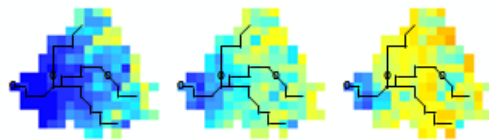

LZFSC
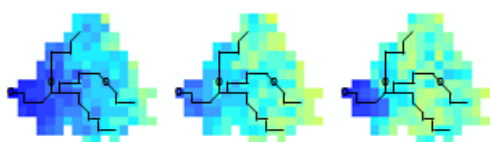

LZFPC
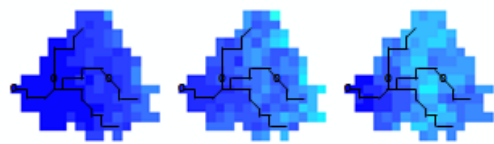

ADIMC
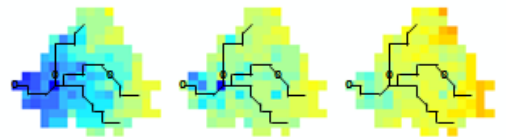

Mean absolute difference of base and updated soil moisture

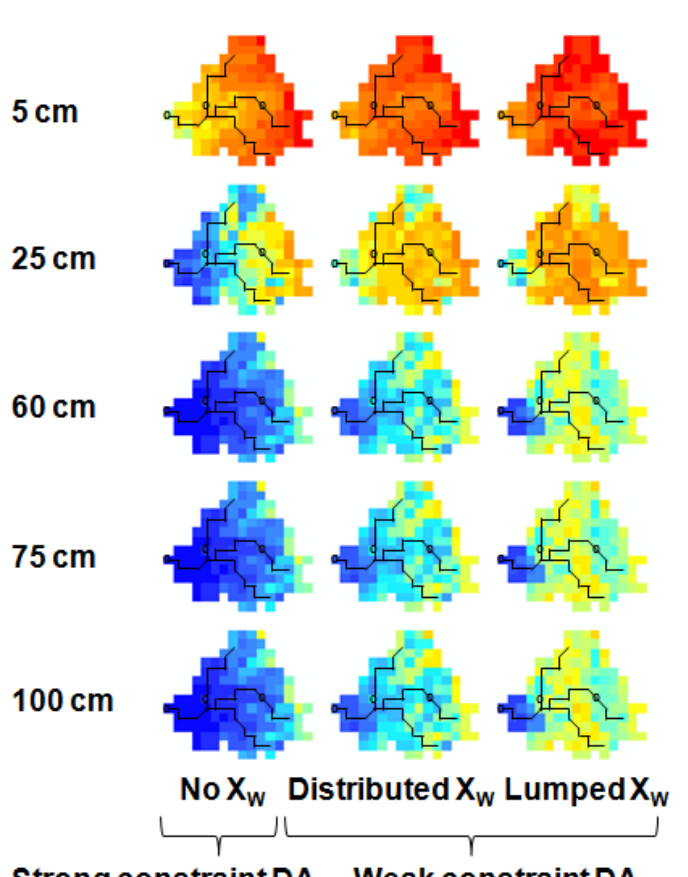

Strong constraint DA Weak constraint DA
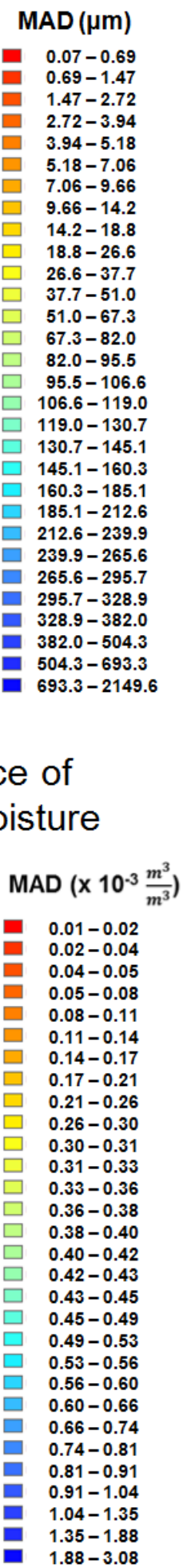

$0.01-0.02$

$0.02-0.04$

$0.04-0.05$

$11-0.14$

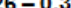

$0.30-0.31$

$0.33-0.36$

$1.88-3.08$ 
Correlation coefficient of

base and updated SAC-SMA model states

UZTWC

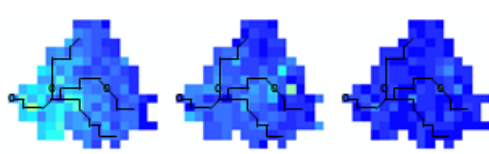

Correlation coefficient $\left(\times 10^{-3}\right)$

UZFWC

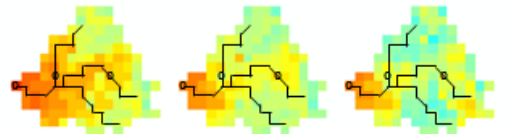

- 792.65-927.71

- $927.71-950.62$

$927.71-950.62$
$950.62-965.12$

- $965.12-972.68$

$\square \quad 972.68-981.98$

$\square \quad 981.98-987.98$

$\square \quad 987.98-990.45$

- $990.45-992.89$

$992.89-994.58$

$\square \quad 994.58-995.58$

口 $995.58-996.66$

$\square 96.66-997.42$

$997.42-997.90$

$997.90-998.48$

$997.90-998.48$
$998.48-998.78$

$998.78-999.17$

$999.17-999.44$

$999.44-999.65$

$99.44-999.65$
$999.65-999.77$

$999.65-999.77$
$999.77-999.85$

$999.85-999.89$

$999.89-999.92$

999.92-

999.9 -

$999.94-999.97$

$999.97-999.98$

$999.98-999.987$

$999.987-999.992$

$999.992-999.998$

- $999.998-999.999$

ADIMC

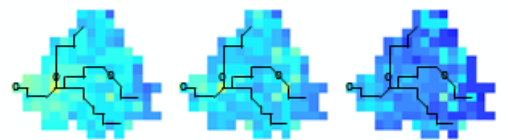

$999.999-1$

Correlation coefficient of

base and updated soil moisture

$5 \mathrm{~cm}$

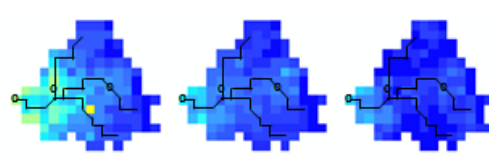

Correlation coefficient $\left(\times 10^{-3}\right)$

$25 \mathrm{~cm}$

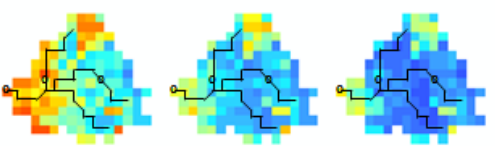

$60 \mathrm{~cm}$

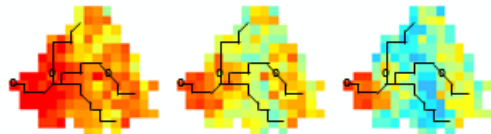

$75 \mathrm{~cm}$

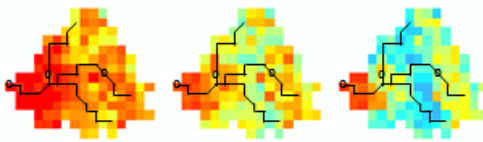

$100 \mathrm{~cm}$

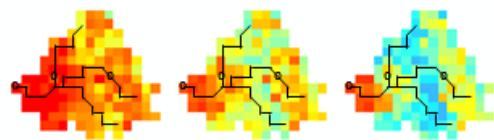

No $X_{W}$ Distributed $X_{W}$ Lumped $X_{W}$

Strong constraint DA Weak constraint DA

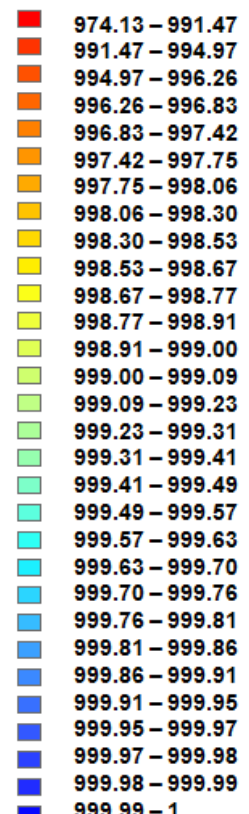



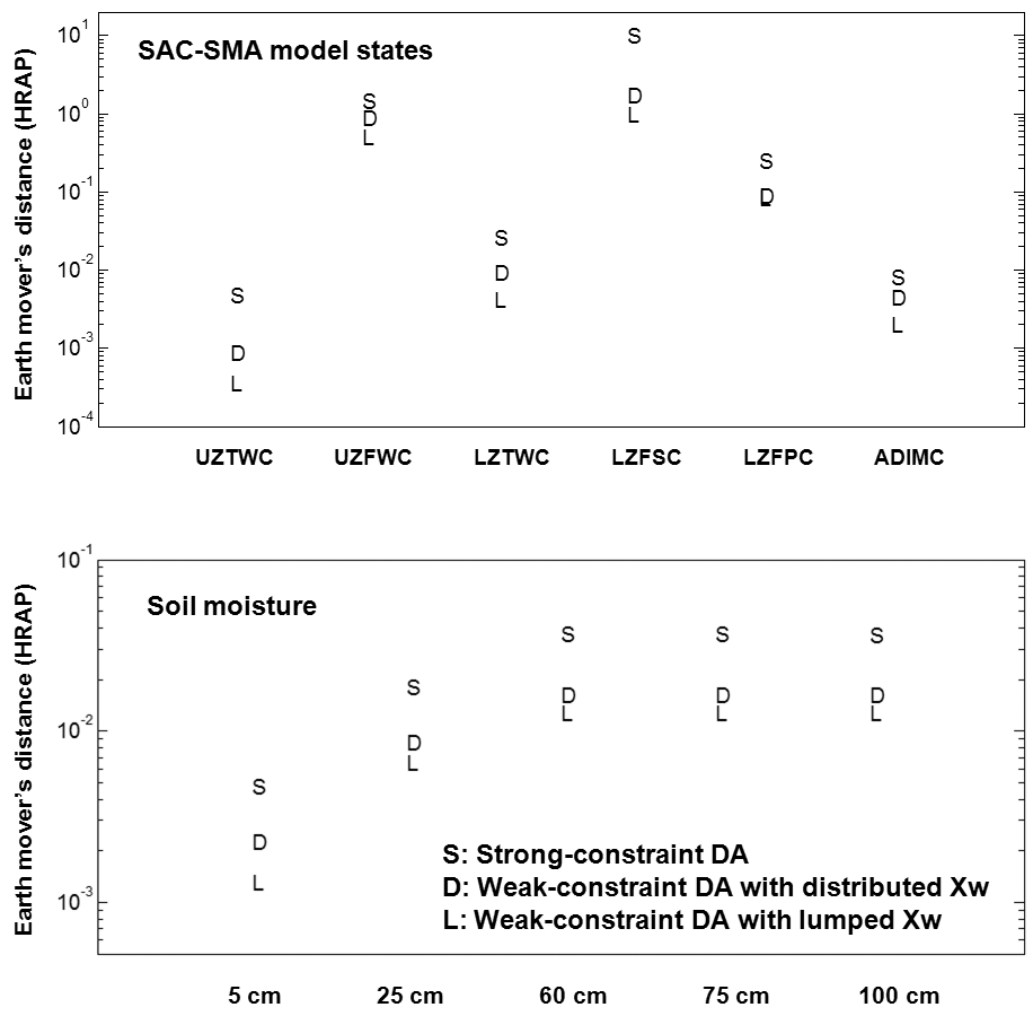


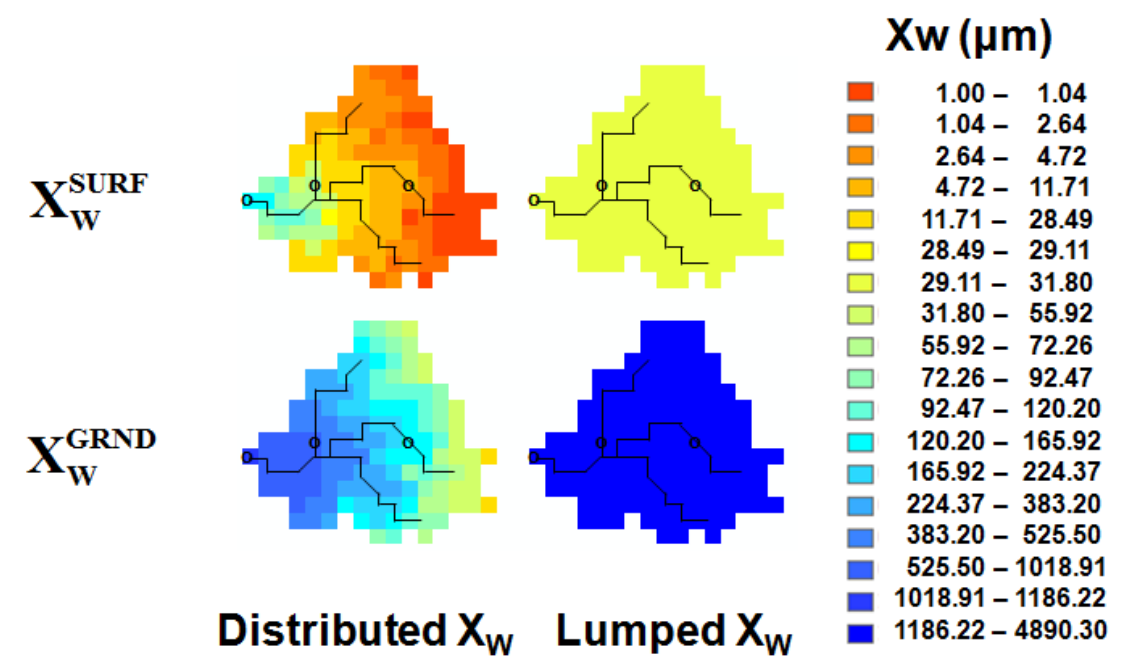


Streamflow analysis

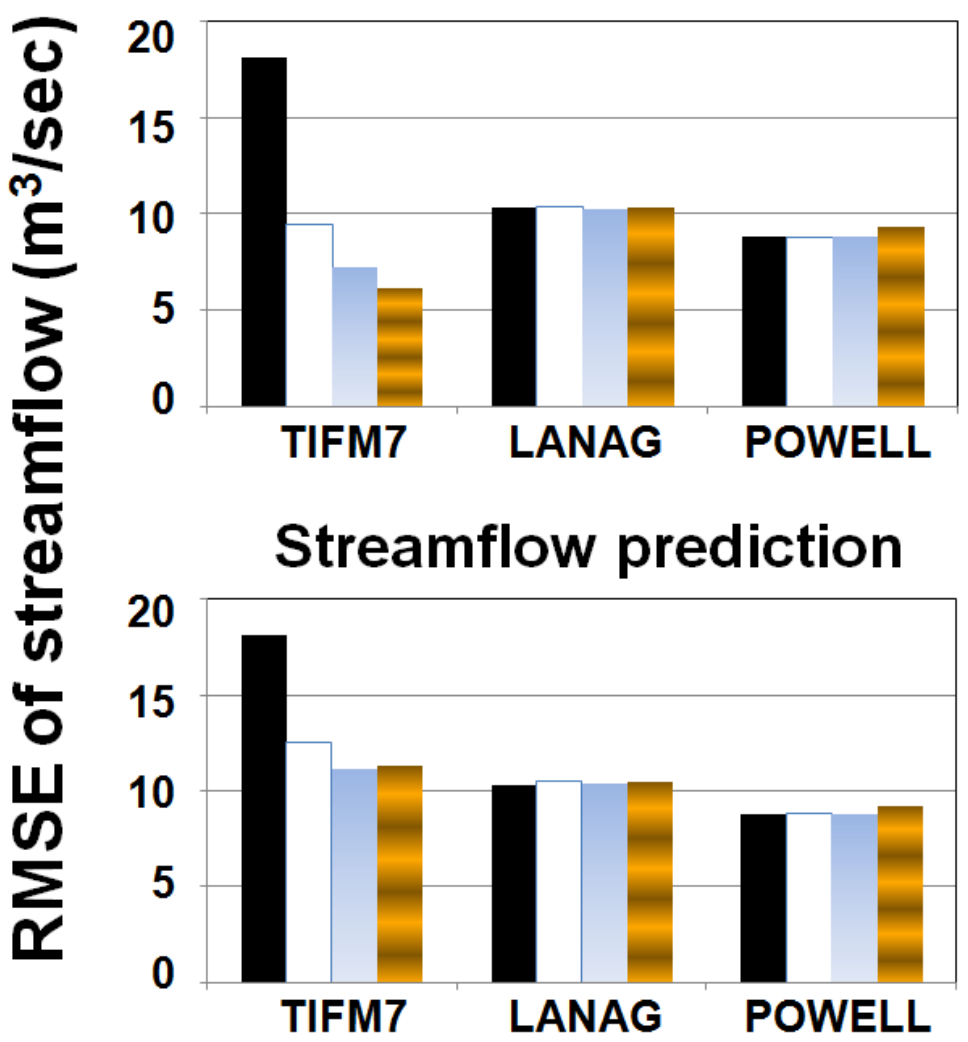

- No DA

$\square$ Strong-constraint DA

Weak-constraint DA with distributed Xw

E Weak-constraint DA with lumped Xw 


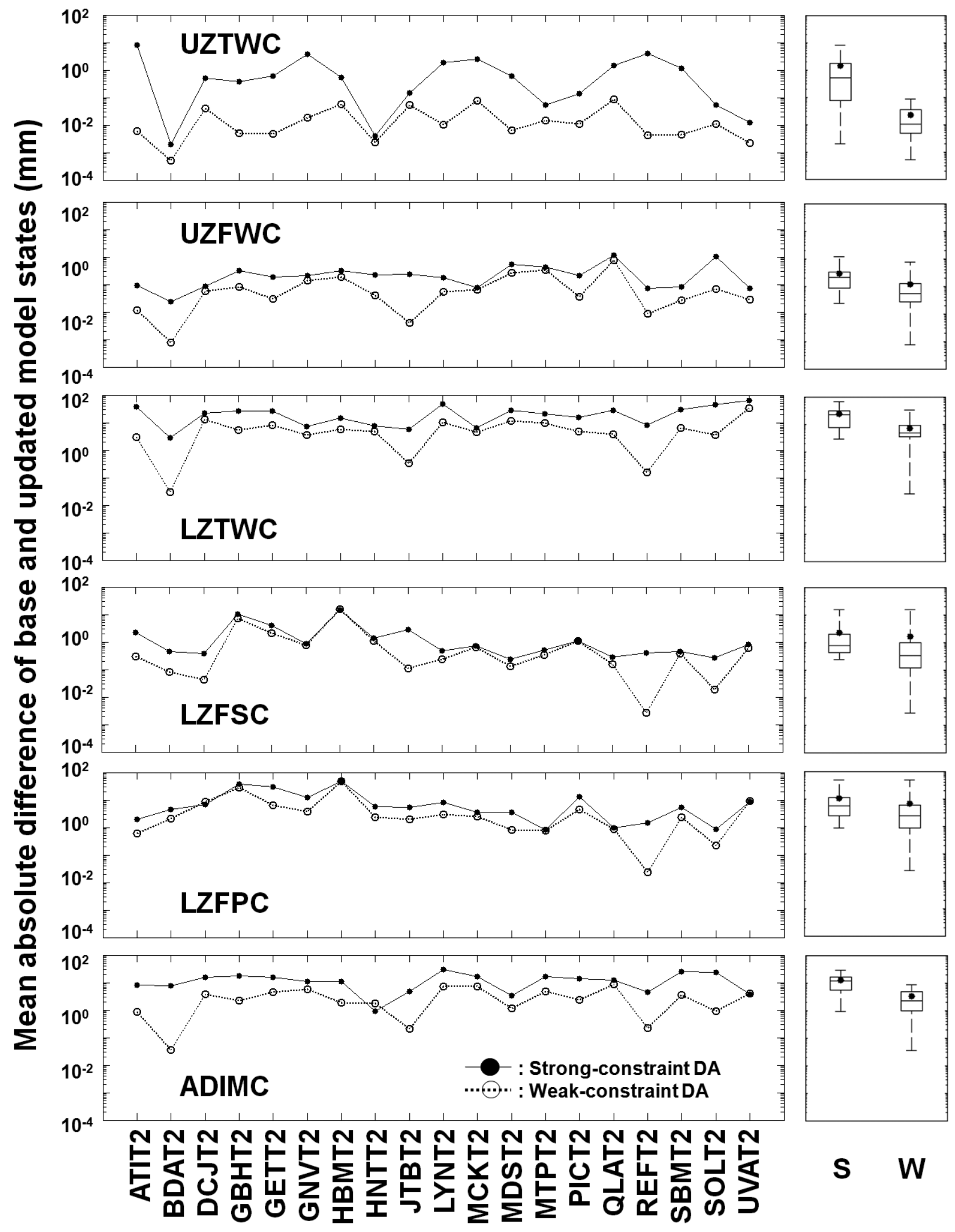




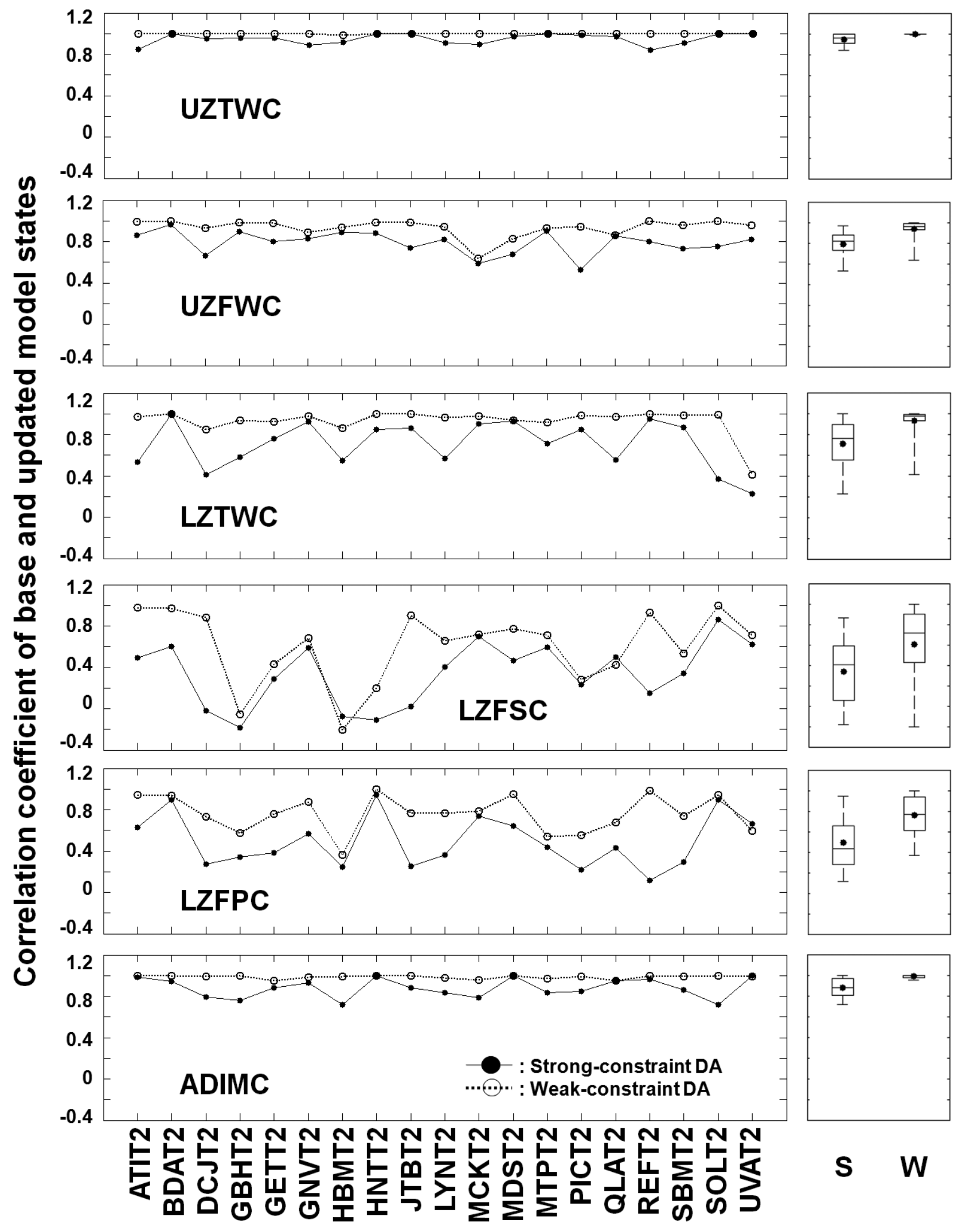




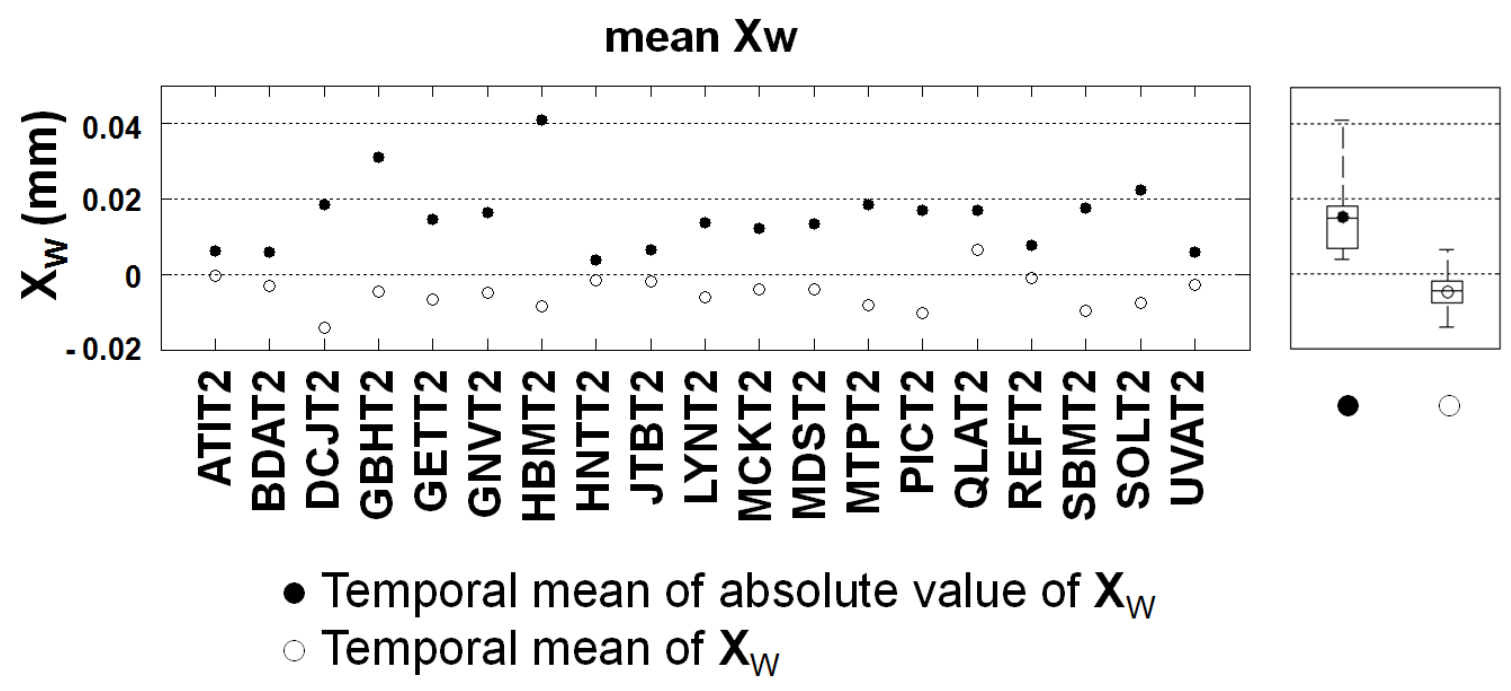


Streamflow analysis

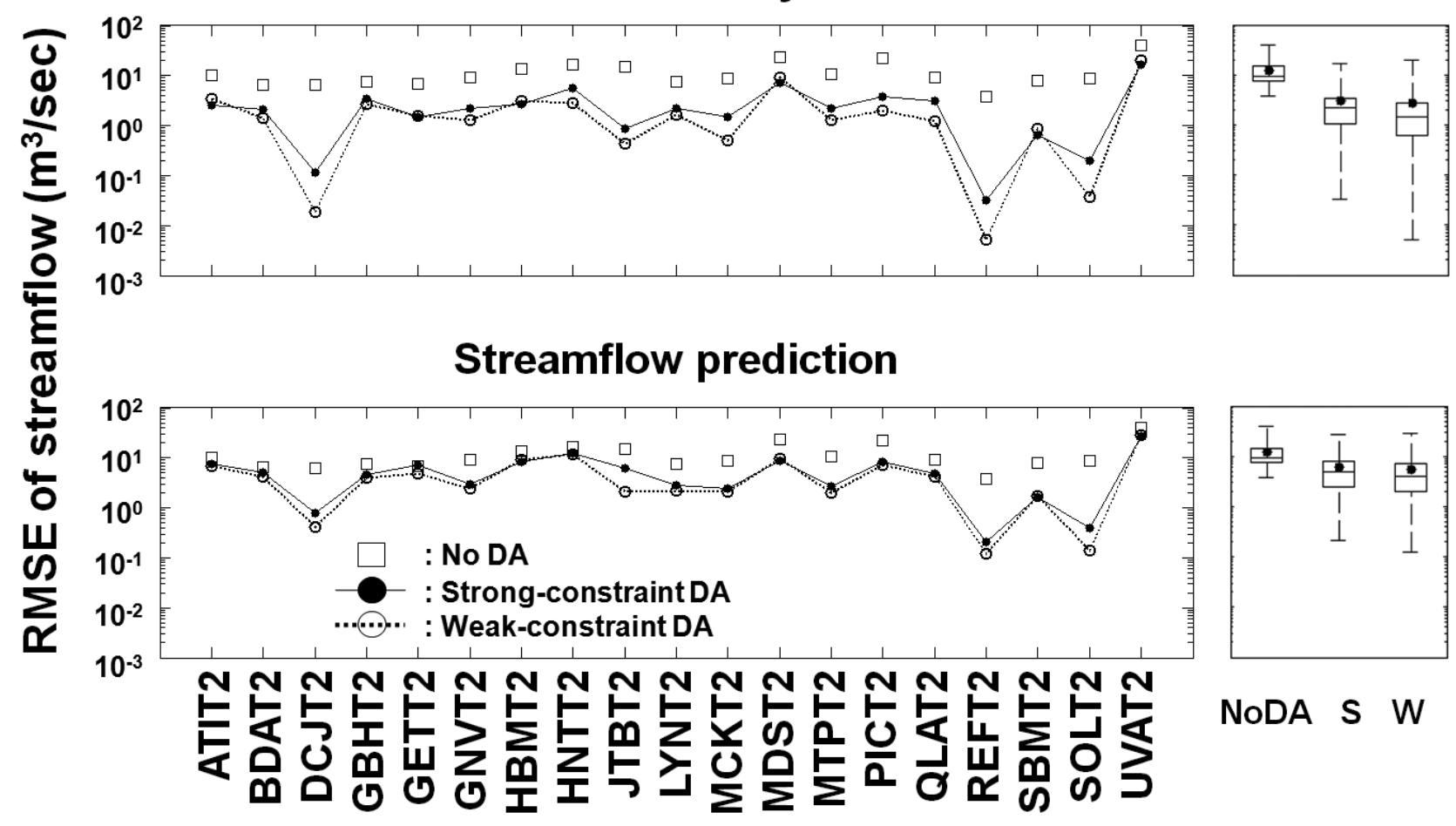




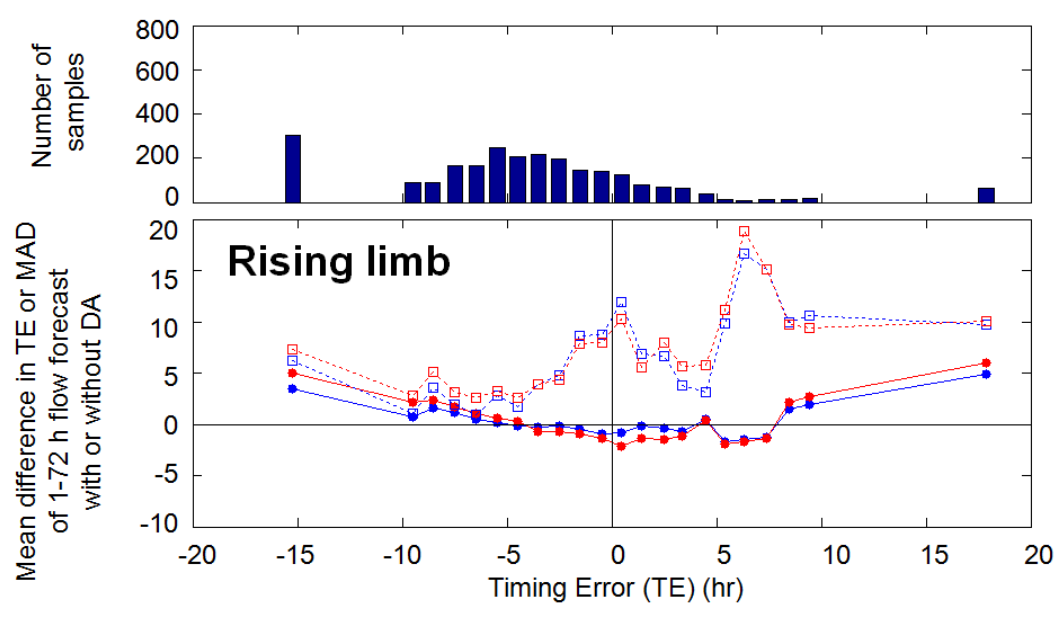

(a)

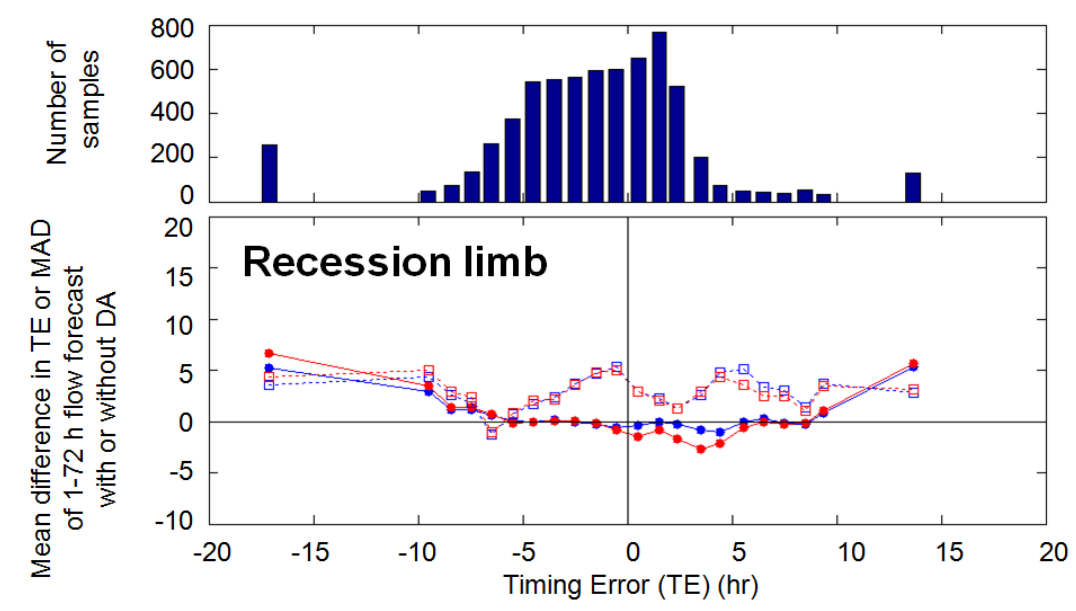

(b)

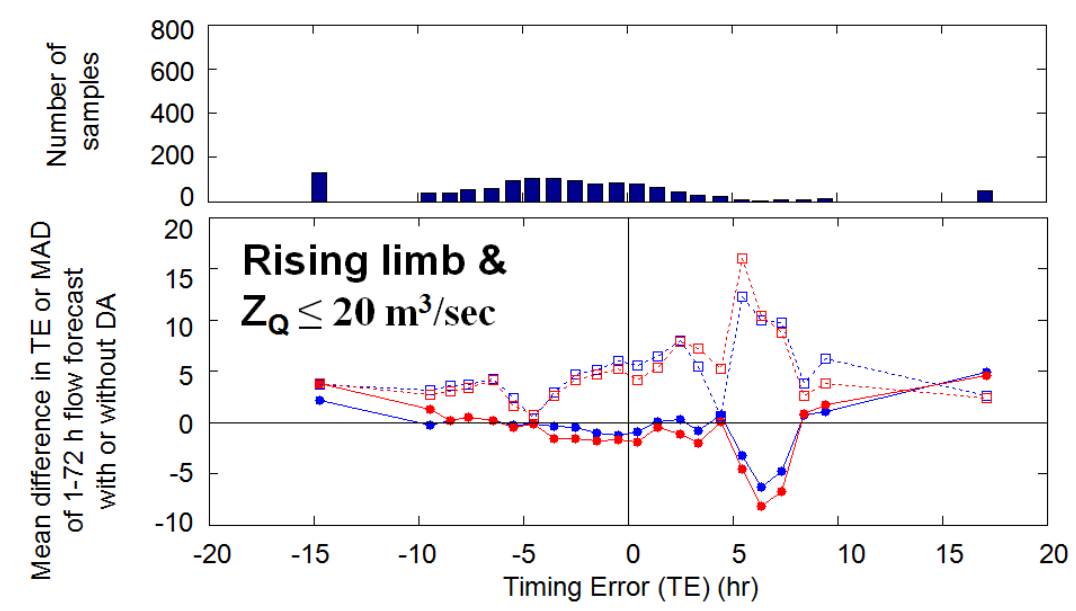

(c)

Mean difference in absolute value of TE of 1-72 $\mathrm{h}$ flow forecasts without or with weakly-constrained DA Mean difference in absolute value of TE of 1-72 $\mathrm{h}$ flow forecasts without or with strongly-constrained DA Mean difference in MAD of 1-72 $\mathrm{h}$ flow forecasts without or with weakly-constrained DA Mean difference in MAD of 1-72 $\mathrm{h}$ flow forecasts without or with strongly-constrained DA 